\title{
Encartes
}

ISSN 2594-2999, Bajo licencia Creative Commons

encartesantropologicos@ciesas.edu.mx

Olvera Gudiño, José Juan; Peña Benitez, Jacqueline

Las vidas del acordeón. Reparadores y vida social de un instrumento musical en Monterrey

Encartes, vol. 4, núm 8, septiembre 2021-febrero 2022, pp. 130-168

Enlace: https://encartes.mx/olvera-pena-reparadores-acordeon-socialmonterrey

José Juan Olvera Gudiño ORCID: 0000-0002-3301-8245

Jacqueline Peña Benítez ORCID: 0000-0002-0521-5778

DOI: https://doi.org/10.29340/en.v4n8.174

Disponible en https://encartes.mx

Este artículo contiene información multimedia, te invitamos a consultarlo en la versión digital. 


\title{
TEMÁTICAS
}

\section{LAS VIDAS DEL ACORDEÓN. REPARADORES Y VIDA SOGIAL DE UN INSTRUMENTO MUSICAL EN MONTERREY}

THE LIVES OF THE ACGORDION. REPAIRERS AND SOGIAL LIFE OF

A MUSICAL INSTRUMENT IN MONTERREY

\author{
José Juan Olvera Gudiño* \\ Jacqueline Peña Benítez*
}

Resumen: Este artículo explora las prácticas y los significados alrededor del oficio del reparador de acordeones en el área metropolitana de Monterrey, México, haciendo uso del estudio cultural de los instrumentos musicales y de la antropología y sociología del trabajo. Describe la diversidad de servicios ofrecidos bajo el término "reparación" y destaca la cantidad y variedad de conocimientos necesarios para mantener o embellecer esta "máquina de sonidos". Asimismo, describe los diferentes caminos para obtenerlos y actualizarlos. En estos procesos pueden identificarse habilidades propias de un técnico en ciertos momentos, o de un artesano en otros; habilidades condicionadas, pero no determinadas, por los procesos globales de fabricación y circulación de este instrumento.

Palabras clave: antropología de la música, antropología de los oficios, acordeón, vida cultural del instrumento, artesanos, Monterrey.

THE LIVES OF THE ACGORDION. REPAIRERS AND SOGIAL LIFE OF A MUSICAL INSTRUMENT IN MONTERREY

Abstract: This article explores the practices and meanings surrounding the trade of an accordion repairer in the metropolitan area of Monterrey, Mexico, using the cultural studies of the musical instrument and the anthropology and sociology of the craft. It describes the diversity of services offered under the term "repair" and highlights the amount and variety of knowledge needed to maintain or embellish this "sound machine". Likewise, it describes the different

* Centro de Investigaciones y Estudios Superiores en Antropología Social-Noreste.

ISSN 2594-2999, Bajo licencia Creative Commons

Encartes 8 •septiembre 2021-febrero 2022, pp. 130-168

Recepción: 29 de abril de 2020 • Aceptación: 13 de julio de 2020

https://encartes.mx

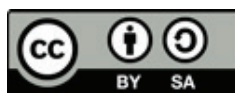


paths towards obtaining and updating them. In these processes, one can, at times, identify the typical abilities of a technician, and other times, of a craftsperson; abilities conditioned, although not determined, by the global manufacturing and marketing processes of this instrument.

Keywords: music anthropology, anthropology of trades, accordion, cultural life of the instrument, craftperson, Monterrey.

A Fosé Garza Santos, Pepe Charango, músico e investigador de la música norestense, fundador del grupo Tayer.

$\mathrm{I}_{\mathrm{H}}^{\mathrm{s}}$ NTRODUCGIÓN

El quinto Festival del Acordeón Hohner, realizado en Monterrey en septiembre del 2019, fue un interesante ejercicio de convocatoria para el abanico de artistas que utiliza este instrumento. Aunque el protagonismo se lo llevó la música de conjunto norteño y los acordeones diatónicos de la compañía transnacional europea, como sucedió en las ediciones recientes, en realidad participó una diversidad de músicos, músicas y acordeones de todo
1. De izq. a der. Gilbert Reyes, representante de Acordeones Hohner; Rubén Piña y Antonio Tanguma III, durante un homenaje al Celso Piña, durante el 5 Festival de acordeones Hohner.

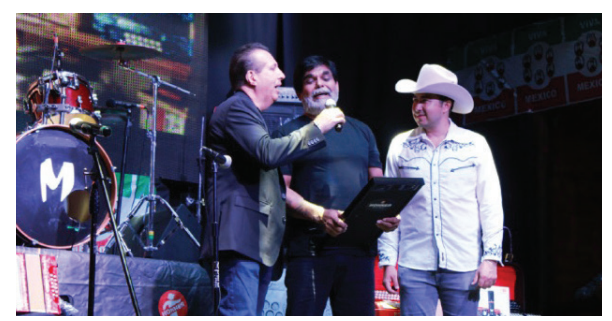

Foto: Jacqueline Peña Benitez.

México y de Monterrey en particular (ver imagen 1). En los últimos 20 años, por lo menos seis festivales musicales anuales se realizan en esta metrópoli. Son eventos con vinculaciones internacionales donde el acordeón diatónico es protagonista, ${ }^{1}$ e ilustran su ascenso como instrumento protagónico de la música popular, más allá de la música regional con la que

\footnotetext{
${ }^{1}$ Nos referimos al Festival Voz de Acordeones, que arrancó en 1998 y ha continuado de manera ininterrumpida; la Muestra Estatal de Fara Fara, organizada desde hace seis años por el Consejo Estatal para la Cultura y las Artes; el Concurso de polka, organizado dentro del Festival Santa Lucía; el Encuentro de Música Norestense, que organiza desde hace seis años el grupo Tayer con entidades culturales estatales o federales, y el Cumbia-fest., que apenas comenzó en 2018.
} 
regularmente se le identificaba. Este protagonismo expresa la expansión de su mercado, tanto en el consumo, con la llegada a México de nuevas marcas y modelos, como en la circulación, con fuertes mercados formales y de segunda mano. En consecuencia, aumenta la demanda de servicios de mantenimiento, reparación y afinación, que rebasa con mucho los esfuerzos de las compañías fabricantes que quieren atenderla. Así, una serie de reparadores surgen con este crecimiento, impulsados por sus propias necesidades y utilizando sus habilidades técnicas y creativas, que se han unido a los que ya tenían más tiempo. Lamentablemente, como sucede con otros instrumentos de la música popular, el estudio del acordeón diatónico desde la academia no es equivalente a su relevancia social; nos referimos en particular a los trabajos que abordan a los reparadores/afinadores, por lo que su relevancia y funciones sociales son poco conocidas y valoradas.

Monterrey y la zona noreste ${ }^{2}$ tienen una importancia crucial para el mercado y la cultura del acordeón, pues convergen aquí tres tradiciones musicales: la del conjunto norteño mexicano, la del conjunto tejano y la de la música popular de la costa atlántica colombiana. ${ }^{3}$ Cada una tiene sonoridades particulares -y sus respectivos referentes culturales- que el técnico debe conocer para atender necesidades específicas de afinación, repara-

${ }^{2}$ Partimos de la idea de que Monterrey es uno uno de los centros o nodos, junto con Houston y San Antonio, de la región noreste, que comprende los estados de Coahuila, Nuevo León, Tamaulipas y el sur de Texas. Está caracterizada por un pasado común, así como por sus actuales e intensas movilidades humanas, de capitales y de bienes materiales y simbólicos, legales e ilegales. Alguna de la bibliografía al respecto puede verse en Arzaluz y Sandoval, 2018; Sandoval, 2012; Cerutti y Hernández, 2001; Hernández-León, 2008.

${ }^{3}$ La música de conjunto norteño es una cultura musical desarrollada originalmente en la región noreste de México que tiene al acordeón y al bajo sexto como instrumentos centrales y que interpreta polkas, redobas, chotices, valses, canciones rancheras, huapangos, boleros y cumbias. Tiene a la música de conjunto tejano como contraparte en el sur de Texas. Finalmente, la música colombiana de Monterrey recupera la música popular de la costa atlántica colombiana e incorpora formas de baile, lenguaje e indumentaria particulares. Para el estudio de las músicas de conjunto norteño y conjunto tejano, más desde la perspectiva historiográfica, puede revisarse Díaz, 2016; Peña, 1996; Ragland, 2009 y 2019; Garza, 2006; Godina, 2016 y en este número de Encartes; Montoya, 2013; Montoya y Medrano, 2018. Para la llamada música colombiana, Olvera, 2005; Blanco, 2013 y 2018. 
ción o restauración. Así, la ejecución de música norteña en un acordeón afinado para música colombiana puede inquietar o molestar al músico, aunque la diferencia pase inadvertida para la gente común.

Este artículo explora las prácticas y significados alrededor del oficio del reparador de acordeones en el área metropolitana de Monterrey, México, así como sus distintas funciones sociales. Describe la diversidad de servicios ofrecidos bajo el término "reparación" y destaca la cantidad y variedad de conocimientos necesarios para mantener o embellecer a esta compleja y costosa "máquina de sonidos". ${ }^{4}$ Asimismo, describe los diferentes caminos que los reparadores siguen para obtenerlos y actualizarlos. En estos procesos pueden identificarse habilidades propias de un técnico en ciertos momentos, o de un artesano, en otros.

El vocablo "reparador", principal palabra con la que se denominan entre sí en esta región, a diferencia de "afinador", por ejemplo, nos habla de que su función social más relevante es alargar la vida de este caro y complejo aparato en el contexto de una sociedad económicamente muy desigual como la mexicana. Al hacerlo, coadyuva a la reproducción cultural de amplios grupos sociales facilitando la ejecución de sus ritualidades y materializando sus creencias y tradiciones, siendo partícipe de un fenómeno donde se intersectan economía, tecnología y arte en países emergentes.

Las preguntas que guían este artículo son: ¿en qué consiste el oficio de reparador de acordeones? ¿Cómo se inserta este oficio en la dinámica musical y simbólica de la región noreste de México? ¿Cómo se vinculan sus trayectorias con los conocimientos obtenidos para la realización de su trabajo? ¿Es su trabajo parte orgánica del ciclo de la industria de los instrumentos musicales o un impedimento para su expansión, al extender

\footnotetext{
${ }^{4}$ Según oxfam (Gerardo Esquivel, 2015), "México está dentro del 25\% de los países con mayores niveles de desigualdad en el mundo". Según varios reparadores entrevistados, pese a la gran variedad de precios, el acordeón es uno de los instrumentos más caros de la música popular en la región. El reparador Daniel Martínez dice, por ejemplo, que podría ser el instrumento más caro de la dotación instrumental en un conjunto. Un acordeón usado de baja calidad, en buenas condiciones, que se usa para aprender y no para tocar en presentaciones, puede costar 4500 pesos y representar más de un mes del salario mínimo que actualmente se paga en México (225 dólares y 184.83 dólares, respectivamente), mientras que uno profesional puede comenzar en 20 mil y terminar en 120 mil (1 000 y 6000 dólares, respectivamente).
} 
la vida útil del acordeón? ¿Cuál ha sido el papel desempeñado aquí por el internet y las redes sociales?

Situamos este trabajo en la convergencia de la antropología del trabajo y de los oficios, de autores como Luis Reygadas (2002, 2012) y Novelo (2006), con el estudio cultural de los instrumentos (Dawe, 2012; Kies, 2013; Bates, 2012; Libin, 2009). La subsecuente exposición del texto seguirá este orden: se desarrollará un marco conceptual basados en el estudio cultural de los instrumentos musicales que articula tres ejes: el estudio del instrumento, sus aspectos técnicos y sus funciones sociales, más allá de los acercamientos tradicionales de la organología; la reparación como parte de la vida social del acordeón y, finalmente, su inserción como práctica económica condicionada por el lugar de trabajo, las relaciones de producción en tanto microempresas con lógicas que van más allá de las ganancias. Todo lo cual genera una particular "cultura del trabajo", con características del técnico y del artesano. Se expondrá la metodología utilizada para obtener la evidencia empírica, la cual se presentará en dos partes. En la primera, con apoyo de una investigación documental en internet, se expondrá un panorama general de los reparadores en el noreste de México y sur de Texas. A continuación, se presentarán los hallazgos surgidos de las entrevistas a cinco reparadores divididos en tres secciones: a) su trayectoria artística y técnico-profesional; b) el modo de vida material, incluyendo la combinación con otros trabajos y su vinculación con otras industrias; y c) servicios que ofrecen y mercados que atienden, así como las tecnologías y los conocimientos que manejan para dar servicio. El artículo cierra con algunas reflexiones sobre el oficio del reparador del acordeón.

\section{El estudio GUltural De LOS INSTRUMENTOS MUSICALES}

La organología es una disciplina encargada de estudiar los instrumentos musicales. De acuerdo con el Diccionario de Música, tiene el cometido de desarrollar "la clasificación de los instrumentos, las bases científicas detrás de éstos, su evolución y sus usos musicales y culturales "(Latham, 2008: 1129). Diversos autores llaman a complementar los aportes de esta disciplina en el sentido de superar, en su visión hegemónica, una orientación mono-cultural y ahistórica, en el sentido de que ignora el contexto sociohistórico que rodea al instrumento en cada periodo social (Bates, 2012: 365). Esta superación incluye recuperar la propia caracterización de los usuarios (Dawe, 2012: 198) o la función social del instrumento (Bates, 2012: 195). 
Así pues, nosotros partimos de un enfoque centrado en el estudio cultural de los instrumentos musicales, el cual los considera como generadores y depositarios de una gran cantidad de significados. Gracias a los instrumentos musicales los humanos creamos sonidos y música con los cuales desatamos una compleja serie de procesos físicos y sociales, por lo que, para Kevin Dawe (2012: 195), pueden ser considerados "sitios de construcción de significados" y encarnación de sistemas de valores y creencias basadas en la cultura.

Los instrumentos son hechos y significados en muy distintas dimensiones, más allá de su función propiamente musical; por ejemplo, incorporan el avance de la tecnología o el cambio de criterios estéticos (Nettl, 2015: 368). Por otra parte, autores como Libin (2009) destacan el papel de los instrumentos musicales como amplificadores de sentimientos y como herramientas que expanden la percepción humana más allá del rango normal sensorial, y así, junto con Bates (2012), subrayan el cambio de su significado y funciones según el contexto sociocultural. De esta manera, Simonett (2012b: 24) resalta el doble carácter que tuvo el acordeón durante el siglo xIX en Europa, primero como expresión de progreso y modernidad, y después como expresión negativa de la cultura de masas, y da así un panorama sobre el significado social del instrumento a través de diferentes épocas.

El paisaje regional actual del acordeón diatónico, siguiendo el concepto de instrumenscapes (Dawe, 2012: 197), está constituido por un gran mercado formal, principalmente de acordeones chinos y europeos; además se vincula a un conjunto de industrias culturales multinacionales y regionales: empresas de espectáculos, foros artísticos, festivales musicales, sellos grabadores, industrias de instrumentos, radio, televisión e internet. En resumen, el panorama de este instrumento es aquel que pasa de una amplia presencia social a una cada vez mayor aceptación o legitimación nacional, sin llegar a aparecer aún de forma seria en los programas de estudio de las facultades de música o de la escuela de Bellas Artes. Una mínima descripción del funcionamiento del acordeón ayudará a entender los aspectos de su reparación, que se abordarán más adelante.

De acuerdo con la clasificación de Hornbostel-Sachs (Deborah, 2020), el acordeón es un aerófono de lengüeta libre (Latham, 2008: 27), pues el sonido se produce al hacer vibrar la lengüeta por una delgada columna de aire, mismo mecanismo que la armónica. 
Según Gabriel Pareyón, el acordeón es

un instrumento musical portátil que consiste en dos tableros rectangulares conectados por un fuelle. Dentro de los tableros hay lengüetas metálicas afinadas que vibran al paso del aire impulsado por el fuelle. El acordeón moderno tiene un teclado [o botones] del lado derecho para tocar la melodía, y botones en el izquierdo para hacer sonar los bajos y acordes tonales precompuestos (Peyron, 2006: 21).

El instrumento que tiene las doce diferentes notas de la escala cromática y, por tanto, puede interpretar las melodías en cualquier tono, recibe el nombre de acordeón cromático y generalmente es de teclas, aunque también los hay de botones. El acordeón diatónico, del que habla este artículo, ofrece escalas limitadas y, por tanto, reduce la posibilidad de tocar en diferentes tonos. Generalmente es de botones y éstos activan sonidos diferentes al abrir o cerrar el fuelle. La cantidad de escalas tonales depende de las filas de botones que hay en el instrumento. El acordeón diatónico contemporáneo más común en la región actualmente tiene tres filas. Se describen ahora los mecanismos de generación del sonido y de su activación mecánica para el acordeón diatónico de 31 botones.

La unidad más pequeña del mecanismo de generación de sonido es llamada "voz". Se trata de una placa o estructura de metal en forma rectangular, que tiene dos rendijas alargadas del mismo tamaño (ver imagen 4).

2. Las distintas partes externas del Acordeón

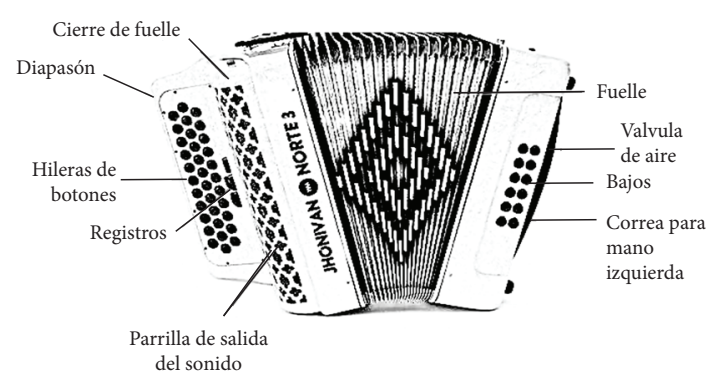

Tratamiento de la imagen de Kat Azul.
4. A estas voces las han retirado sus protectores

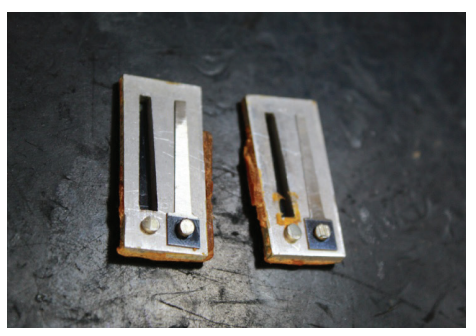

Fotos: Jacqueline Peña Benitez. 
$\mathrm{Al}$ frente y al reverso de estas rendijas hay una lengüeta metálica, que es la que genera el sonido cuando pasa aire por ella. A cada lado, la otra rendija se tapa con una especie de lámina de papel, cuero u otro material, que son válvulas para impedir el paso del aire (ver imagen 5). Ahora, el sonido que escuchamos al presionar un botón y extender el fuelle hacia afuera es en realidad la unión de dos voces simultáneas con afinaciones ligeramente diferentes. Otro par de voces diferentes se escucha al cerrar el fuelle. Hay acordeones que activan tres voces por botón. Unos y otros se usan para la música norteña, tejana y colombiana, aunque los ejecutantes de esta última cultura musical usan más el de tres voces.

Las voces se colocan en bloques o estructuras de madera, también llamados "burros", que se ordenan hasta en tres hileras o filas para el acordeón diatónico de 31 botones (ver imágenes 7, 8 y 9), y hasta seis en otros tipos de acordeones (Simonett, 2012a: 3). El acomodo sigue la altura o agudeza de las voces y está sellado con cera, entre voz y voz.

7. Retirando los burros del interior del acordeón.

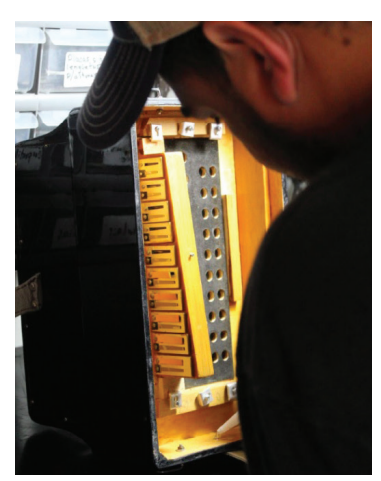

Foto: José Juan Olvera.
8. Voces acomodadas en su estructura, también llamada "burro"

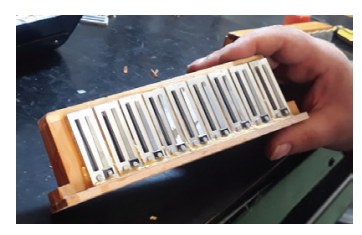

Foto: Jacqueline

Peña Benitez.
5. Las protecciones que se ven son, en este caso, de cuero amarillo. Algunas han perdido su firmeza y se observan medio levantadas. Protegen a la lengüeta metálica que está del lado posterior de la voz (que no se ve). La lengüeta metálica que sí se ve, tiene una protección similar al otro lado

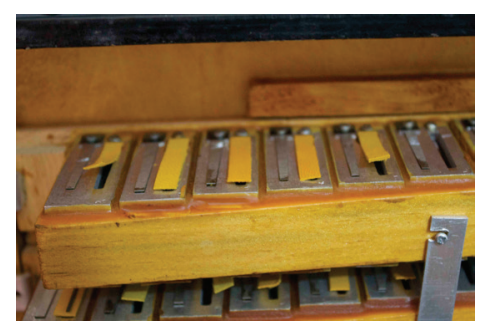

Fotos: Jacqueline Peña Benitez
9. Voces retiradas de sus estructuras. Por debajo de esa estructura de madera, entra el aire que hace vibrar las lengüetas, generando los sonidos

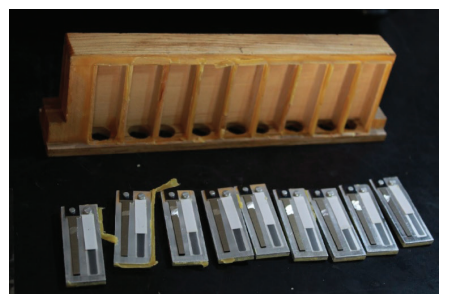

Foto: Jacqueline Peña Benitez. 
El procedimiento de sellado permite que cuando el aire entra al mecanismo no suene nada, salvo que se oprima uno de los botones y éste, mediante un brazo metálico similar al de las teclas de la máquina de escribir, levante una o varias válvulas que permiten al aire tener acceso a las voces y hacerlas vibrar. Así, mientras el fuelle genera el aire, los botones indican qué sonidos activar. Finalmente, ciertos acordeones tienen mecanismos para activar sólo una de las voces, generando un sonido más agudo o grave, o hacer combinaciones de sonidos. Tales mecanismos aparecen por encima de las hileras de botones (ver imagen 2). Estos mecanismos se denominan registros y permiten variaciones de sonidos dentro de la misma estructura del acordeón. Así, tanto el conjunto interno de las voces como los mecanismos periféricos que las activan o las hacen variar generan, en esencia, el sonido de este instrumento. Lo anterior explica que la reparación del sistema de voces o de los mecanismos que las generan necesiten de un técnico capacitado.

Debemos poner atención al hecho de que el acordeón nunca se ha producido en México; es un bien importado desde que se inventó, hace casi 200 años. Caso diferente al de la laudería, donde grupos de constructores mantienen y desarrollan en México conocimientos sobre el funcionamiento del instrumento, los materiales de que está hecho y las formas de construir y reparar (Hernández-Vaca, 2008: 226). Tales conocimientos, en el caso del acordeón, sirven para reparar, pero no para fabricar la unidad entera. Aunque las grandes marcas de acordeones ofrecen servicios de reparación en general, quien repara no siempre es el que construye y no necesariamente está avalado por él. De hecho, la mayoría de las veces no es así. Está avalado por la red de consumidores de ese servicio, algunos de ellos grandes artistas, y también por reparadores que se recomiendan entre sí cuando están muy ocupados o no pueden ofrecer el servicio, como ya lo notó Ragland en el sur de Texas (2019: 17).

\section{LA REPARACIÓN DEL ACORDEÓN}

GOMO PARTE DE SU VIDA SOCIAL

En su estudio histórico y antropológico sobre la vida social de las cosas, Arjun Appadurai (1991) propone una perspectiva totalizadora que abarca sus distintas transformaciones, incluyendo su condición mercantil o su candidatura para tenerla. La cultura, sostiene, establece un determinado sistema de significados dependiendo del contexto más profundo o superficial que hace que las cosas se hagan o no mercancías, o funcionen o no 
como mercancías. A ese contexto o marco Appadurai le llama régimen de valor. Acompañan al régimen de valor las rutas culturalmente establecidas que deben tener las cosas para su uso y movilidad, incluyendo su eventual convertibilidad en mercancías, así como las desviaciones de esas rutas, que efectúan o son impulsadas por ciertos sectores sociales. De acuerdo con el autor, la tensión entre las rutas y las desviaciones daría vida a buena parte de la actividad económica de una sociedad, a la innovación y al cambio cultural. Proponemos aquí que la reparación del acordeón forma parte de su vida social, de su trayectoria o su biografía (Appadurai, 1991; Kopytoff, 1991); y de hecho será una exigencia para que continúe tal trayectoria. Planteamos también que la llegada de los acordeones chinos a México (más baratos, de menor calidad y menor vida), ha alterado las rutas tradicionales del uso y movilidad de este bien. Hasta hace unos 20 años, el acordeón prevaleciente ha sido de origen europeo, generalmente de marca Hohner, de buena calidad y hecho para durar diez años o más. Por ello, generalmente es caro y se le repara y embellece por razones económicas o sentimentales, pues en su extensa vida logra sedimentar las vivencias y los afectos de quienes lo han poseído. Así, en contextos como el mexicano la reparación de un acordeón podría constituir una desviación, pues alarga el periodo de obsolescencia del bien, sobre todo si está fabricado para durar pocos años. Este punto será desarrollado más adelante.

Retomamos el término emic de "reparación", usado por la mayoría de los técnicos entrevistados, para definir una serie de procesos posteriores a su fabricación, que convierten al instrumento musical en un bien más funcional y con mayor valor por haber sido intervenido en, al menos, uno de estos cuatro tipos de servicios: a) Los relativos a los mecanismos centrales de generación de sonidos que, como vimos arriba, son llamados "voces", sea mediante su reparación o mediante lo que podemos llamar generación de "estéticas sonoras"; b) los que atienden mecanismos periféricos que permiten la activación de estas voces; c) aquellos que se vinculan con la restauración y con la estética visual del acordeón y, finalmente, d) una serie de servicios extras, como la venta de refacciones y accesorios. ${ }^{5}$

\footnotetext{
${ }^{5}$ Algunos de estos servicios incluyen la venta de acordeones, usados o nuevos, que no representan intervención alguna, pero los incluimos aquí porque forman parte de las actividades del negocio de algunos reparadores.
} 
Así pues, bajo el término genérico de "reparador" tenemos también las acciones de afinador, restaurador y personalizador o decorador. Sus labores tienen que ver con la técnica como artesanía, pero también con la técnica del técnico (Ortega y Gasset, 2000); es decir, de aquellos que viven en la época en la que no sólo se crean instrumentos, sino máquinas. El reparador de acordeones repara, de hecho, una máquina. En este trance, el reparador está más del lado del obrero que del genuino técnico; más del lado del que aplica, siguiendo planes y modos de hacer ya establecidos por los diseñadores e ingenieros, conocimientos a los que no tiene fácil acceso. Ejecuta muchas de las cosas del obrero: por ejemplo, al cambiar botones viejos por nuevos, según un diseño preestablecido. Pero también es capaz, como el diseñador o inventor, de solucionar problemas para poner tres botones nuevos (o sea, seis nuevos sonidos) ahí donde no los había. Es verdad que sigue los lineamientos técnicos para mantener los mismos mecanismos, pero piensa, planea y ejecuta la solución del problema de cómo romper la coraza, dónde ubicar los nuevos orificios y cómo acomodar los mecanismos siguiendo las especificaciones ya señaladas en la sección anterior. Al fusionar ambos conocimientos, se parece más al artesano, sin hablar de las condiciones de trabajo y de su unidad doméstica, de las cuales hablaremos más adelante.

Siguiendo a Morten Riis (2013: 259-260), el reparador está en medio del funcionamiento y los diversos estados de mal funcionamiento, de ahí su relevante papel. Como veremos en la sección de hallazgos, a través del desarrollo de lo que Riis denomina "ontología del accidente" el reparador consigue una comprensión más profunda de la tecnología en sí misma, al encontrar nuevas posibilidades para el entendimiento de cada cosa, pieza o mecanismo y la razón por la que están rotos o no funcionan, ya sea que el acordeón tenga una obsolescencia programada más acelerada o no.

Por su lado, la propuesta sociológica de Howard Becker (2008) sobre los mundos del arte abre otra perspectiva útil para este trabajo. Su análisis está centrado en los procesos sociales y organizacionales relativos a los mundos artísticos. Separa artes y oficios; estos últimos son para él sinónimos de artesanía. Un producto artesanal comprendería los aspectos de ser funcional o útil, demostrar "control extraordinario sobre materiales y técnicas" gracias al conocimiento y la habilidad, que él llama virtuosismo, y, finalmente, el desarrollo de una estética (Becker, 2008: 312-314). Cuando se pone el acento en este último aspecto, los artesanos se pueden convertir en "artesanos artistas". El trabajo de los reparadores dedicados a la estética artesanal puede 
entrar en la categoría de arte cuando restaura, personaliza o decora. Este "arte menor", según Becker, funcionaría siempre y cuando sea aceptado como tal por sus congéneres y haya instituciones que lo validen. En este sentido, podemos hablar, además de los festivales del acordeón, de un sinfín de museos dedicados al instrumento que exhiben piezas tanto por su valor histórico como por su valor estético, así como de una legitimación desde la plástica, en el sur de Texas, que ha durado por lo menos 25 años. ${ }^{6}$

Por más que el ejecutante del instrumento -y no el reparador- sea considerado tradicionalmente como "el verdadero artista", aquél requiere de las habilidades de éste para su desempeño artístico. En tal sentido, Cathy Ragland (2019) propone visualizar a los afinadores de acordeón del sur de Texas como mediadores culturales que, gracias a sus habilidades técnicas y a su profundo conocimiento de la cultura musical en la que están insertos (la del conjunto tejano o la del conjunto norteño), son capaces de modificar el sonido de un acordeón para evocar con él al sonido de un legendario músico, vivo o muerto. Ragland sostiene que de esa manera se conserva y enriquece lo que Josh Khun llama imaginario sónico o audiotopía, ya sea de las comunidades mexicoamericanas o las mexicanas de reciente migración (Kuhn, citado en Ragland, 2019: 3-4).

El contexto donde se efectúa la reparación suele ser el taller técnico/ artesanal, lo que condiciona parte de los procesos socioeconómicos de generación de valor (ver imagen 10). Estos talleres serían microemprendimientos organizados por personas que se autoemplean (Rodríguez, 2001), pero que se van transformando en microempresas que atienden al sector de la música y de la industria del espectáculo.

\footnotetext{
${ }^{6}$ Algunos son el Museo del Acordeón de Tacheng de Xinjiang, donde se exhibe lo mejor de la fabricación rusa, italiana, china, alemana, ucraniana, entre otros orígenes; el World of Accordion Museum de Wisconsin, Minnesota, (que tiene también una escuela de técnicos reparadores); The Accordion and Harmonica Museum. Malden, de los Países Bajos; el Museo del Acordeón Anconetani, de Buenos Aires, Argentina y el Finnish Accordion Museum. Sysmä, de Finlandia. Por otro lado, existe un premio de artes plásticas, otorgado desde hace 39 años por el Guadalupe Cultural Arts Center, donde el acordeón ha sido el protagonista de las propuestas estéticas para los carteles de sus eventos, que pueden verse en https://www.sacurrent.com/sanantonio/all-35-tejano-conjunto-festival-posters-1982-2016/Slideshow/3269728, consultado el 25 de junio de 2021.
} 
Estas microempresas, aunque funcionan con la lógica de la ganancia y buscan valorizar el capital, comparten pautas de otras economías, propuestas por Polanyi (1976: 6-7), como las de reciprocidad, lo cual incluye intercambios sin mediación del dinero, o préstamos y servicios ofrecidos sin cobro a cuenta de algún favor futuro, etc. Victoria Novelo (2003) señala características de la cultura del artesano mexicano, que coinciden en gran parte con lo hallado en este estudio, y que son:

$\mathrm{El}$ individualismo, el secreto del oficio, la
10. Una parte del taller de los hermanos Aguillón. Aquí, René Aguillón en el proceso de afinación

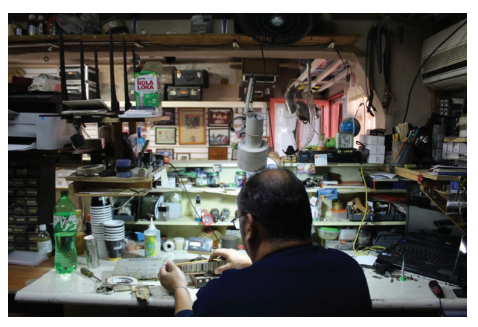

Foto: Jacqueline Peña Benitez defensa del control personal de los ritmos y las cargas de trabajo, el uso de una rudimentaria contabilidad, la preferencia por las relaciones cara-a-cara con el consumidor y por tanto, la dificultad para planear la producción regular para un mercado anónimo, el proceso de trabajo como una parte de la economía doméstica y otras prácticas que siguen operando entre los artesanos. (Novelo, 2003: 15)

Todas estas interacciones sociales conforman una "cultura del trabajo" (Reygadas, 2002: 106) donde se articulan, según el autor, el modo como el proceso laboral repercute en la producción de significados, las influencias de la cultura sobre la actividad productiva y el contexto sociohistórico específico en el que se desenvuelven tales prácticas y significados, en medio de conflictos y negociaciones (Reygadas, 2002: 119).

En resumen, la reparación de un acordeón contribuye a recuperar o modificar su significado, ampliar sus funciones sociales y extender su vida social. La función social del reparador consiste, entonces, en alargar la vida del instrumento, recuperar la memoria musical regional, desarrollar en él estéticas visuales o sonoras y hacer funcionales instrumentos inservibles, pero de valía por razones distintas.

\section{Consideraciones metodológicas}

El acercamiento etnográfico para este trabajo incluyó entrevistas en profundidad con cinco reparadores de diferentes edades y que habitan en 
diversos puntos del área metropolitana de Monterrey. Las entrevistas duraron en promedio una hora y media y fueron llevadas a cabo entre enero de 2016 y diciembre de 2019. Los acercamientos iniciales a los entrevistados se llevaron a cabo gracias a músicos e investigadores como José Garza (Pepe Charango), del grupo Tayer, que difunde la música tradicional norestense y con amplio conocimiento en el mundo de los instrumentos y de los reparadores. Estos encuentros fueron realizados en sus talleres, por lo menos en dos ocasiones para la mayoría de los casos. Allí nos permitieron, además, tomar fotos y video. $\mathrm{Al}$ terminar los borradores correspondientes a cada uno, los llevamos con ellos para cotejarlos y para honrar un acuerdo inicial de eliminar o al menos no hacer explícitos ciertos procedimientos, herramientas o materiales que querían mantener para sí. Varias de las observaciones y conversaciones se llevaron a cabo mientras el reparador evaluaba o arreglaba acordeones, ajenos o llevados por nosotros. Para un mejor entendimiento, los autores tomamos cursos de ejecución en los niveles de principiante e intermedio con uno de los reparadores quien es, además, ejecutante y profesor.

Por otro lado, hicimos uso extensivo de la investigación documental para el noreste mexicano, fundamentalmente en el ámbito de internet, con fines de contextualizar lo que ocurre en Monterrey. El registro incluyó reparadores de acordeón, número aproximado, localización y principales servicios ofrecidos. Gracias a estos registros fue más sencillo ubicar los talleres que operan en la región y en Monterrey, centro de nuestro estudio. Reforzamos el registro con datos de otros investigadores (Ragland, 2019; Ramos, 2016). La investigación arrojó al menos 42 reparadores o talleres de reparación en la región noreste, comprendiendo los estados de Nuevo León, Tamaulipas, Coahuila y el sur de Texas. De ellos, aproximadamente 19 talleres están situados en Monterrey y en su área metropolitana, incluidos los cinco reparadores de este estudio, como puede verse en el mapa 1.

Recopilamos y sistematizamos en una tabla los servicios ofrecidos por los reparadores en sus páginas y la contrastamos con la matriz surgida de las entrevistas, observando que ésta incluye todo lo que "nominalmente" menciona el grupo más grande en sus páginas electrónicas (ver tabla 1). Es decir, no hallamos un servicio que no fuese ofrecido por estos cinco entrevistados, corroborando lo atinado de nuestra muestra. Estos materiales han sido complementados con dos entrevistas a vendedores de instrumentos musicales en Monterrey y San Antonio, Texas, y otros dos reparadores, 
Mapa 1. Servicios de reparación de acordeón en el noreste de México

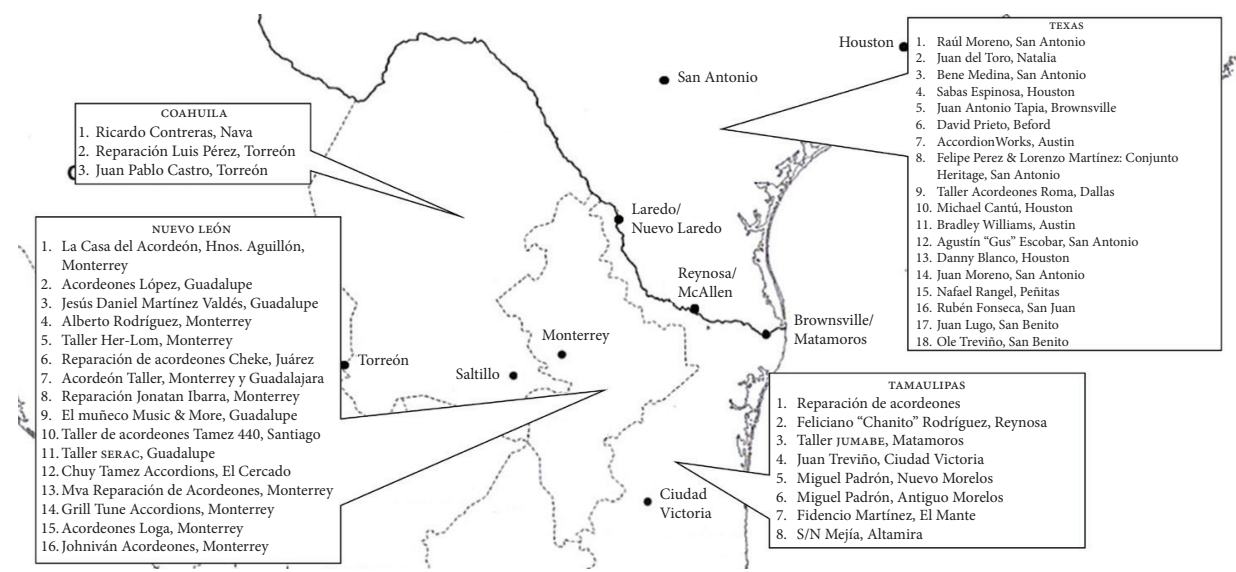

Fuente: Elaboración propia con base en páginas de internet y redes sociales digitales. Para el caso de Texas, los nombres de 10 al 18 fueron tomados del artículo de Regland (2019). Los nombres del 3 al 8, en el caso de Tamaulipas, fueron proporcionados por el historia dor Francisco Ramos Aguirre.

Tabla 1. Servicios que ofrecen los reparadores de acordeones

\begin{tabular}{|c|c|c|c|}
\hline $\begin{array}{c}\text { Referentes } \\
\text { al sistema de } \\
\text { sonidos o voces }\end{array}$ & $\begin{array}{c}\text { Referentes a los } \\
\text { mecanismos de activación } \\
\text { de las voces y la estructura } \\
\text { física }\end{array}$ & $\begin{array}{l}\text { Estética visual del } \\
\text { instrumento }\end{array}$ & Servicios extra \\
\hline $\begin{array}{l}\text { Afinación gene- } \\
\text { ral / alteración }\end{array}$ & $\begin{array}{l}\text { Mantenimiento general del } \\
\text { acordeón }\end{array}$ & $\begin{array}{l}\text { Cambio o reposición de } \\
\text { cintas del fuelle }\end{array}$ & $\begin{array}{l}\text { Venta e } \\
\text { instalación de } \\
\text { refacciones }\end{array}$ \\
\hline $\begin{array}{l}\text { Conversiones } \\
\text { de cromático } \\
\text { a diatónico / } \\
\text { cambio de tono }\end{array}$ & Reparación de fuelles & $\begin{array}{l}\text { Restauración de acordeones } \\
\text { viejos }\end{array}$ & $\begin{array}{l}\text { Fabricación de } \\
\text { estuches para } \\
\text { el acordeón }\end{array}$ \\
\hline $\begin{array}{l}\text { Reparación de } \\
\text { voces rotas o } \\
\text { sustitución del } \\
\text { juego de voces }\end{array}$ & Reparación de botones & $\begin{array}{l}\text { Personalización (la } \\
\text { decoración de acordeones } \\
\text { con base en el gusto del } \\
\text { cliente). El cliente puede } \\
\text { decirle qué color quiere } \\
\text { para su acordeón, }\end{array}$ & $\begin{array}{l}\text { Venta de } \\
\text { instrumentos } \\
\text { musicales } \\
\text { (acordeones y } \\
\text { bajoquintos) }\end{array}$ \\
\hline
\end{tabular}


Las vidas del acordeón. Reparadores y vida social de un instrumento musical en Monterrey

\begin{tabular}{|c|c|c|c|}
\hline \multirow[t]{2}{*}{$\begin{array}{c}\text { Referentes } \\
\text { al sistema de } \\
\text { sonidos o voces }\end{array}$} & $\begin{array}{c}\text { Referentes a los } \\
\text { mecanismos de activación } \\
\text { de las voces y la estructura } \\
\text { física }\end{array}$ & $\begin{array}{c}\text { Estética visual del } \\
\text { instrumento }\end{array}$ & Servicios extra \\
\hline & & $\begin{array}{l}\text { algún acabado en particular, } \\
\text { si le gustaría que le grabaran } \\
\text { un nombre, si quiere } \\
\text { aplicaciones en cintas, } \\
\text { pegatinas o pedrería, correas } \\
\text { y broches de algún estilo en } \\
\text { particular, entre otras cosas. }\end{array}$ & \\
\hline $\begin{array}{l}\text { Igualación } \\
\text { de sonido, } \\
\text { octavación }\end{array}$ & $\begin{array}{l}\text { Cambio de brazos del } \\
\text { acordeón }\end{array}$ & $\begin{array}{l}\text { Personalización (la decoración } \\
\text { de acordeones con base en el } \\
\text { gusto del cliente). El cliente } \\
\text { puede decirle qué color quiere } \\
\text { para su acordeón, algún } \\
\text { acabado en particular, si le } \\
\text { gustaría que le grabaran un } \\
\text { nombre, si quiere aplicaciones } \\
\text { en cintas, pegatinas o } \\
\text { pedrería, correas y broches } \\
\text { de algún estilo en particular, } \\
\text { entre otras cosas. }\end{array}$ & $\begin{array}{l}\text { Venta de } \\
\text { accesorios } \\
\text { para el } \\
\text { acordeón }\end{array}$ \\
\hline $\begin{array}{l}\text { Cambio de } \\
\text { registros }\end{array}$ & $\begin{array}{l}\text { Cambio de cera } \\
\text { Restauración de madera } \\
\text { Restauración del acordeón } \\
\text { (implica reparación de ma- } \\
\text { dera vieja, parrillas } \\
\text { oxidadas o deterioradas, } \\
\text { funcionamiento general del } \\
\text { instrumento, cubrir fugas } \\
\text { de fuelles, suplir correas y } \\
\text { broches muy viejo, rotos o } \\
\text { ausentes) } \\
\text { Fabricación de varillas } \\
\text { (para reponer los brazos } \\
\text { del acordeón) }\end{array}$ & Trabajos de pintura nacarada. & \\
\hline
\end{tabular}


en Reynosa y San Antonio, que no se incluyen en forma extensa aquí, pero que nos ayudaron a contrastar y delimitar los datos a exponer.

La siguiente sección presenta las trayectorias educativas y laborales, técnicas o artísticas, que dibujan el perfil de los reparadores, pues ayudan a comprender el acento en algunos de sus servicios o la presencia de algún aspecto material o administrativo de su negocio. Las presentamos hasta el momento en que toman la reparación de acordeones como parte importante o central de su modo de vida. A partir de ahí, describimos los servicios ofrecidos y mostramos las vinculaciones con otras actividades e industrias relacionadas con la música, con el mercado que atienden y, finalmente, con la diversidad de conocimientos que les permiten mantener su negocio.

\section{TRAYECTORIAS Y SERVICIOS DE LOS REPARADORES}

Ricardo y René Aguillón López (Monterrey, 1973 y 1970) son hijos del reconocido reparador Santos Aguillón (Monterrey, 1939), quien se dedicó a esta actividad desde mediados de los años 50 del siglo pasado hasta el año en que murió (2016). René cursó hasta la secundaria mientras que Ricardo terminó la preparatoria técnica. Aunque trabajaron parcialmente como reparadores, ambos tuvieron experiencias laborales en contextos fabriles y tiendas de antigüedades. Finalmente - gracias a la labor de su padre, quien supo acercarlos poco a poco- decidieron dedicarse al negocio ya establecido y hoy intentan enseñar a sus hijos sobre el arte y negocio de las reparaciones. Los hermanos Aguillón tienen también linaje musical, pues su padre y su abuelo fueron músicos de acordeón y tocaron en diferentes etapas de su vida. Sin embargo, aunque saben tocar un poco el bajo sexto y la batería, ninguno de ellos se dedicó a la música, y en cambio sí han mantenido un interés por especializar sus destrezas en torno al oficio de reparadores. Reconocen a Rogelio Rodríguez, originario de Allende, como uno de los pioneros en esta actividad en la región y quien dio importantes pistas a su padre sobre las reparaciones (De la Fuente, 2015). Su taller se ubica en la colonia Moderna de la ciudad de Monterrey

11. Los hermanos Ricardo (Der.) y René Aguillón López, en su taller

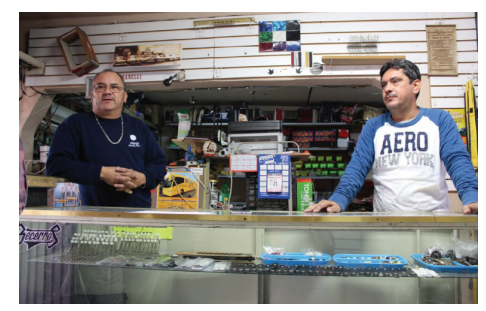

Foto: Jacqueline Peña Benítez. 
desde 2009, aunque su padre atendió la reparación durante casi 50 años en el mercado del municipio de San Pedro, Nuevo León.

Herbey López Morin (Monterrey, 1983) nació en el seno de una familia de músicos sonideros ${ }^{7}$ y ejecutantes de música colombiana. Aprendió a tocar el acordeón de manera autodidacta a partir de los 12 años y lo abrió para conocer su mecanismo. A los 15 se integró al conjunto de su familia tomando conocimientos de los acordeonistas que iban pasando por el grupo. Éste se desintegró y a partir de ahí lidera una nueva agrupación. El interés por los instrumentos pasó de la guitarra a las percusiones y de ahí al acordeón, pero sin educación musical formal. Su trayectoria artística se combinó siempre con trabajos de mecánica, carpintería, albañilería y electrónica, de la cual tiene estudios técnicos incompletos. Antes de dedicarse a la reparación fue cliente del taller de Santos Aguillón. Comenzó a reparar con éxito en su casa de la colonia Independencia. Un integrante de la Ronda Bogotá, grupo del reconocido cantante y acordeonista Celso Piña, lo observó y le encargó reparar uno de sus acordeones. El resultado positivo le permitió encargarse de la reparación y el mantenimiento de los instrumentos de ese artista. Finalmente abandonó los otros trabajos que le daban sustento y trasladó su taller a un lugar más concurrido, donde trabaja de tiempo completo desde hace siete años.

12. Herbey López, (izquierda), aparece en su foto de portada de Facebook, junto con Celso Piña

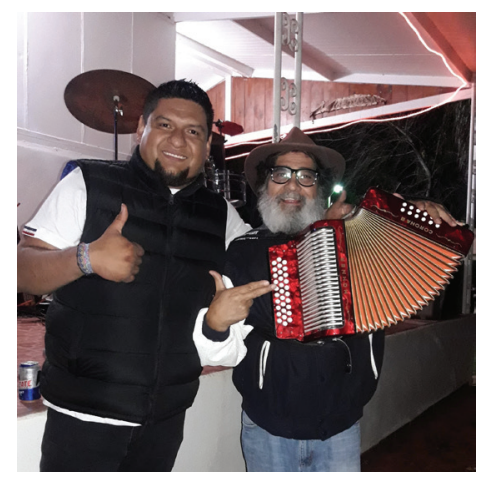

Foto: Jacqueline Peña Benítez.

Daniel Martínez Valdés (Monterrey, 1976) es músico e hijo de un músico "tropical". Se inició en esta actividad a los 7 años, aprendiendo los acordes de la guitarra y tocando el güiro en el conjunto de su padre. En la adolescencia se incorporó a una rondalla y organizó tríos y rondallas con amigos

\footnotetext{
${ }^{7}$ Personas que animan fiestas con sus equipos de sonido, sus recursos orales, su colección de discos y su conocimiento enciclopédico de la música, en este caso de la costa atlántica colombiana.
} 
y vecinos, razón por la cual fue contratado para dar clases de música en el Seguro Social. Entre 1991 y 2014 se dedicó a la música como maestro y ejecutante en grupos y tríos. Compró su primer acordeón a los 16 años. Era un Hohner Corona 2 alemán, usado, que estaba de oferta. Con la necesidad de arreglarlo y la curiosidad de conocer su funcionamiento -algo común en la mayoría de los entrevistados-, comenzó a buscar gente que se especializara en la reparación de acordeones. Conoció a una persona que, pese a que nunca le quiso enseñar a tocar, logró que le enseñara a reparar. A partir de 1998 comenzó a obtener ganancias por ese trabajo mientras era empleado de logística de almacenes. Desde
13. Daniel Martínez en su taller

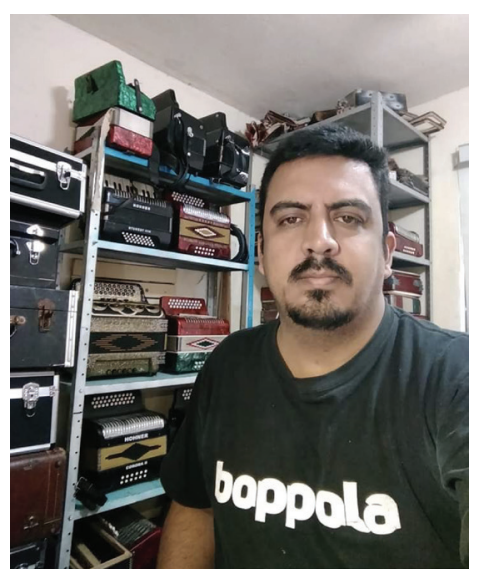

Foto: Jacqueline Peña Benítez. 2014 se dedica enteramente a su taller de acordeones. Es el más acreditado en Guadalupe, Nuevo León. La marca italiana Boppola ha querido que se convierta en uno de sus técnicos oficiales, sin reparar otras marcas. Ha viajado a Italia y observado sus talleres. Actualmente negocia algún acuerdo para obtener maquinaria y herramental especializado, a cambio de sus servicios. No ve su oficio como competencia respecto al trabajo de los demás; al contrario, les orienta y en ocasiones también les pasa material, confirmando prácticas económicas de reciprocidad (Polanyi, 1976) ya señaladas en el apartado teórico. Por internet ha enseñado a interesados en otras partes del país. El día del maestro siempre recibe felicitaciones de personas a quienes ha enseñado. Manifiesta sentirse muy orgulloso de ser ya un referente de la reparación de acordeones.

Fhoniván Sáenz (Monterrey, 1989). Nació en la colonia Independencia. Ésta podría denominarse la zona de barrios populares más importante del noreste de México por la cantidad de expresiones culturales que en ella conviven, como la de música colombiana, que nació ahí y generó tradición antes de expandirse a otros lugares. Así, Sáenz estuvo rodeado de la cultura del acordeón norteño, de la llamada "Colombia de Monterrey" y de otros grupos de moda que, a mediados de los años 90, incorporaban 
la tradición del acordeón con una variedad de géneros urbanos en clave de rock, dentro de lo que se denominó "Avanzada Regia". ${ }^{8} \mathrm{El}$ acordeón lo conoció a los seis años y lo aprendió "de oído". Tuvo su primer instrumento a los 15. Pronto se dio a conocer como acordeonista con grupos dentro y fuera de su localidad en diversos eventos, particularmente en festivales internacionales de acordeón como los de Nueva York o Valledupar (Colombia). Allá vivió seis meses aprendiendo en talleres y escuelas de acordeón. Comenzó el estudio académico del acordeón en la facultad de Música de Monterrey a los 18 años, con el acordeonista bielorruso Sergei Tibets. Esto le permitió expandir su capacidad de ejecución a los acordeones cromáticos y otros tipos de diatónicos, como el bandoneón. Con el tiempo, fusionó lo empírico que aprendió de los festivales con su formación académica y lo fue pasando poco a poco a su proyecto de enseñanza en una academia de acordeón. El taller de reparación surgió hace cuatro años para atender sus necesidades propias como músico, las de sus alumnos y las relativas a la venta de acordeones. Observó que, para el caso del acordeón de música colombiana, en Monterrey no se conocía mucho su afinación particular y él no estaba satisfecho con las reparaciones solicitadas. Después de llevar algunos a un reconocido taller, comenzó a ir aprendiendo gracias a los consejos de los reparadores mismos. Por otro lado, los alumnos de su academia le presentaban de manera continua problemas muy diversos de reparación y afinación, a los que debía dar salida para que sus clases continuaran. Finalmente, la venta de acordeones mandados a fabricar por él a China, como se verá más adelante, incluye una revisión previa de su funcionamiento y una afi-

\footnotetext{
${ }^{8}$ La colonia Independencia se ha señalado como una "caja de resonancia", tanto por la forma de sus cerros como por la rutinaria emisión de música todo el día, principalmente colombiana (Contreras, 2010: 158).
} 
nación particular según el sonido donde el acordeón, tentativamente, se desenvolverá: norteño o colombiano.

Jesús (Chuy) Tamez (Santiago, N. L., 1978) tiene su taller en El Álamo, cerca de Monterrey. Como antecedentes dentro de la música, mencionó que su tío abuelo fue miembro fundador de la agrupación Los Montañeses del Álamo, y su abuelo tocaba la armónica. Tiene estudios de secundaria. A partir de ahí se dedicó a trabajar como chofer y posteriormente como pintor para un fabricante local de ataúdes, actividad que le ayudó a obtener conocimientos que posteriormente aplicaría a su oficio con los acordeones. Lleva trabajando como restaurador de acordeones ocho años, habiendo tenido varias sucursales de casas de instrumentos a lo largo de ese tiempo. Actualmente concentra su actividad económica-laboral en su taller de restauraciones, de donde obtiene los ingresos totales para mantener a su familia.

\section{SERVIGIOS QUE OFREGEN LOS REPARADORES DE AGORDEONES}

Para esta descripción seguiremos la tipología de servicios establecida.

a. Los referentes al mecanismo central de generación de sonidos o "voces". Serían los trabajos propios de un afinador, que en esta investigación encontramos siempre ligados a las demás actividades. Pueden dividirse en reparaciones y alteraciones. Las primeras atienden, por ejemplo, una voz rota por el desgaste natural, la mala calidad de sus metales o el mal uso del fuelle del acordeón, entre otras razones. La voz se suple quitando el remache que la sostiene y volviendo a remachar una nueva lengüeta para finalmente afinarla como estaba la anterior (ver imagen 16 y video 10). Ocurre también que el sellado que está al lado de la lengüeta, en la otra rendija, puede haberse vencido o deteriorado, alterando el sonido. Colocar cotidianamente el acordeón en una posición incorrecta hace que la gravedad venza a este mecanismo que impide el paso del aire (hecho de cuero, cartón o plástico y coloca- 
do también mediante un remache). Habrá que suplirlo por otro. Se demanda también la afinación general del instrumento (ver imagen 6) y/o el cambio de tonos, servicios que podemos ubicar como de "estética sonora". El cambio de tonos se refiere a la conversión de una tonalidad prestablecida o con la que sale de la fábrica a otra que sea de la preferencia del cliente, porque se asemeja al sonido de cierto género musical o de un músico en particular. Entramos al terreno de las alteraciones. Es el caso de Herbey López cuando le piden que el acordeón intervenido suene "como Cadetes de Linares, como Invasores de Nuevo León, como Alegres de Terán... yo le llamo el norteño viejo". Aquí se puede pedir que un acordeón con sonido norteño suene más "tejano" o "atejanado". A este reparador también le mandan audios o videos de canciones de música de Colombia para que afine el acordeón exactamente con ese sonido. En este sentido, encontramos servicios similares a los hallados por Ragland (2019) en Texas, pero no están sistematizados para cada artista específico, como los tienen los afinadores texanos y, en ese sentido, no son tan sofisticados. Así, el trabajo de igualación es imitar exactamente la combinación de sonidos generados al pisar botón; recordemos que, según el tipo de acordeón, por cada botón se hacen sonar dos o tres lengüetas. Por ejemplo, para el sonido clásico norteño, Jhoniván habla de afinar una lengüeta a 440 hertzios, digamos, el número exacto de vibraciones, y la otra a 443, 444. La diferencia entre los dos sonidos o entre tres, si es el caso, que se escuchan al unísono, es lo que le da el toque específico al sonido del acordeón. Este tipo de trabajos incluyen la octavación, que es la afinación de dos notas iguales en ciertos botones, pero una o dos octavas por arriba o por debajo del tono. ${ }^{9}$ En este caso, la intervención altera el sonido de las voces al limarlas levemente de la parte superior o inferior, si se quiere subir o bajar la tonalidad. Al revisar una voz fallida, el reparador puede diagnosticar otro tipo de problemas en el mecanismo de las voces. Por ejemplo, que la cera colocada para sellar,

\footnotetext{
${ }^{9}$ Aquí se puede revisar un caso de octavación realizado por uno de los reparadores de Guadalupe, Nuevo León, que aparece en nuestro registro, al que se le pidió una octavación estilo Dos Gilbertos, grupo tejano muy popular. Ver "Afinación de acordeón 2 Gilbertos", de Taller SERAC: https:/ /www.youtube.com/watch?v=1y9qEX4MpL8, consultado el 30 de noviembre de 2020.
} 
entre voz y voz, ya sea inservible y deba reemplazarse o que haya más voces dañadas u otras descomposturas. En este caso, los reparadores entrevistados dicen que siempre es preferible decir la verdad al cliente y ofrecer una serie de alternativas de solución y distintos presupuestos para que él decida.

b. Los que atienden mecanismos periféricos que permiten la activación de estas voces y, por tanto, la funcionalidad del instrumento. En este caso se arreglan fugas en el fuelle, que hacen escapar o dejan entrar el aire, disminuyendo la intensidad de la nota y dificultando la ejecución. El fuelle puede repararse de una manera parcial o íntegra, volviendo a poner material más resistente en cada una de sus partes. Otros servicios demandados son remplazar o desatorar botones, que quedan trabados bajo el diapasón o agregar nuevos, así como suplir o reparar los brazos que abren las válvulas, que pueden romperse por distintos motivos (ver imagen 22). Es común que durante las etapas iniciales los reparadores construyan piezas del material que tengan a la mano (brazos, lengüetas, botones, etc.), haciendo uso de su ingenio y técnica, y son aquí, nuevamente, técnicos y artesanos. Recordemos que Monterrey es una ciudad industrial que tiene arraigadas tradiciones del trabajo técnico y del reciclaje de materiales desde sus fábricas y talleres, para diferentes usos, entre ellos la música.

c. La restauración y la decoración y personalización. La restauración busca volver a poner en marcha un acordeón muy viejo o usado. Puede o no incluir reparaciones de todo tipo, pero también se restaura un acordeón con materiales nuevos y/o de mejor calidad: remplazar maderas, ceras, limpiar el mecanismo. En el proceso se realizan varias actividades que mejoran su estética, como el cambio de botones o del material que envuelve a muchos acordeones, hecho de celuloide, que muchos llaman "nácar". Los instrumentos intervenidos muchas veces son de buena calidad o con gran valor sentimental para el propietario. La decoración y la personalización ponen el acento más en la estética del instrumento, 
no tanto en su funcionalidad, como pedir cambio de las cintas que adornan un fuelle que funciona bien, pero que el cliente quiere verlo con otra apariencia. También se pueden colocar al frente del instrumento signos de identidad (nombres, logos), poner parrillas más atractivas, entre otros aspectos. En estos procesos la pintura es una herramienta fundamental por su capacidad para la personalización, dibujando paisajes, retratos o plantillas prehechas por el decorador. Por ello, es un servicio cada vez más demandado. Chuy Tamez, quien se dedica principalmente a ofrecer estos servicios, admite que en ellos "hay mucho arte; yo mismo he hecho mis propios diseños y ha resultado que a la gente le agradan mucho" (ver imágenes 20 y 21). El trabajo de Chuy y otros reparadores como él pondría el énfasis. Según Becker, "en la belleza tal como se la representa en la tradición de un arte específico, en las tradiciones e intereses del mundo de arte como fuente de valor, en la expresión del pensamiento y el sentimiento de alguien, así como en la relativa libertad del artista de la interferencia externa en el trabajo" (Becker, 2008: 315).

Retomando el caso de construcción de guitarras artesanales en Paracho, Michoacán, Kies (2013) propone que tales bienes son susceptibles de ser personalizados según especificaciones o necesidades del cliente, cosa que no se solía hacer en una fábrica. Este proceso de valorización particular contrastaba con la uniformidad de la fabricación en serie. Sin embargo, últimamente las grandes compañías de acordeones (como las de teléfonos celulares, computadoras y muchos otros bienes) ofrecen al cliente la oportunidad de escoger
22. Mecanismos de botones y válvulas para acordeón

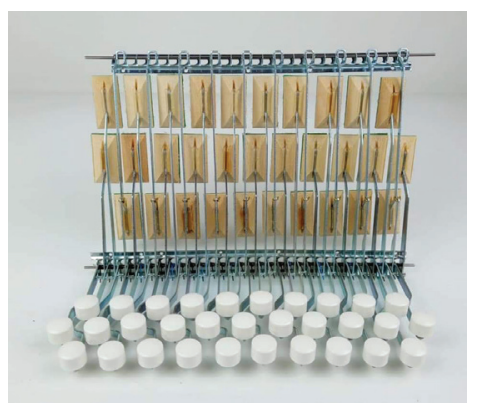

Foto tomada de la página de Jhoniván Sáenz
19. Decoración de acordeón en el taller de Chuy Tamez

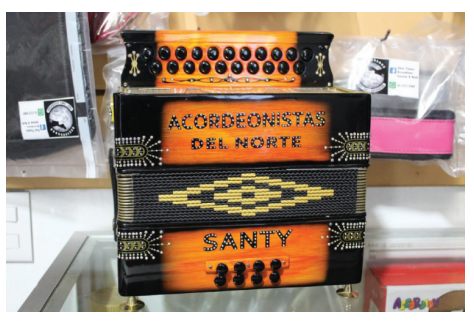

Foto: Jacqueline Peña Benitez. 
color, diseño y algunos otros aspectos del instrumento. Por ello, la personalización desde la fábrica puede haberse establecido como modo de acercarse al cliente y diferenciarse de otras ofertas manufactureras que ignoran este nicho de necesidad estético-afectiva. En este caso, podríamos decir que las fábricas y los reparadores de acordeones compiten en tal aspecto para personalizar el instrumento, rivalizando unas con materiales originales, de su propia marca, y los otros con creatividad y originalidad, además de precios bajos. ${ }^{10}$ Restauración, decoración y personalización están más vinculadas a la nostalgia, al placer estético y al sentido de trascendencia, y no tanto al sentido práctico de extender la vida funcional del acordeón.

d. Venta de refacciones y de acordeones. Un cuarto nicho que contribuye al aumento en los ingresos de los reparadores de acordeones es dedicarse a ofrecer otros productos y servicios relacionados con el instrumento, tales como la venta de acordeones o de instrumentos en general y la construcción, venta e instalación de accesorios y refacciones como correas, broches, estuches y mochilas. En palabras de Herbey López, "el acordeón es mucho trabajo en cuestión de lo que pida la persona, es un instrumento muy completo. Los accesorios también son buena fuente de ganancia, pues si no hay mucho trabajo de reparación, aun así pueden venir a comprar refacciones".

${ }^{10}$ Pueden consultarse en línea las personalizaciones que Hohner ofrece de su acordeón Anacleto. Por lo general las personalizaciones se orientan a las gamas alta y media alta. Ver "Acordeones Personalizados", en Anacleto Accordions: http://es.anacletoaccordions.com/ acordeones/acordeones-personalizados/, consultado el 30 de octubre de 2020. 


\section{Modo De VIDA MATERIAL DE LOS REPARADORES}

¿Qué caracteriza al modo de vida material de los reparadores? Una demanda creciente de sus diversos servicios, al grado de que ellos y sus familias pueden sostenerse de este negocio. Al parecer, una de las causas de ese aumento en la demanda es la cada vez mayor oferta de acordeones chinos -entre 40 y $60 \%$ del mercado, según los reparadores-, generalmente más baratos que sus rivales europeos, pero también de menor calidad y más rápida necesidad de reparación. Lo anterior explicaría por qué varios reparadores ahora están de tiempo completo en sus talleres, cuando antes compartían el tiempo con otras actividades. Llama la atención, además, la relativa juventud de estos entrevistados. Ninguno tiene más de 50 años y el promedio de edad es de 35. Lo anterior contrasta con lo hallado por Ragland en su estudio de los reparadores del sur de Texas, donde pocos están debajo de los 60 años de edad (2019: 14).

Aunque todos trabajan en un abanico de actividades alrededor del acordeón, algunos buscan ir perfeccionando la oferta de ciertos servicios, cuando los ven más rentables o cuando tienen mayor destreza y conocimiento en ellos. Los que como Herbey y Jhoniván, que además son músicos, tienen un abanico laboral aún más grande, pero también sufren las presiones naturales de dos actividades sumamente celosas y exigentes. Finalmente, aunque todos conocen y afinan los acordeones para las respectivas músicas, tejana, colombiana y norteña, el conocimiento profundo de ellas es muy desigual. Todos se iniciaron en el acordeón realizando varias actividades laborales paralelas, formales o informales, que abandonaron para dedicarse por entero a la reparación. Un caso particular es el de Jhoniván Sáenz. En su caso, la reparación es secundaria, más reciente que sus otras actividades, y forma parte de un proceso retroalimentante en el que, según el entrevistado, no hay necesariamente un orden jerárquico de los ingresos que obtiene entre tocar, reparar, vender o enseñar. Según explica, si no llega un alumno a su academia, él puede cobrar por una tocada; si no tiene ninguna fiesta, puede vender algún acordeón, si no hay ventas del instrumento, puede aún vender accesorios, o bien llega alguien a pedir una afinación o una reparación, etcétera. Este proceso se retroalimenta en cada una de las fases. Por ejemplo, cuando toca en algún lugar, alguien le conoce y lo busca para aprender a tocar. A lo anterior se vinculan los ciclos estacionales bajo los cuales los reparadores trabajan: por ejemplo, después del fin de año, cuando los músicos han tenido mucho trabajo, 
compran o reparan instrumentos; otro ejemplo es la época de festivales, o el fin o principio de cursos escolares estadounidenses o en México, allí donde las escuelas incluyen clases de música. ${ }^{11} \mathrm{El}$ conocimiento de estos ciclos estacionales es clave para la supervivencia económica en términos de la estabilidad en el ingreso.

Los reparadores llevan a cabo su trabajo en talleres que tienen entre uno y tres cuartos, y uno o más empleados (ver imagen 14). La mayoría de los locales están separados de sus casas. Las áreas de trabajo de los reparadores pueden dividirse por funciones. Por lo general, un cuarto hace de centro reparador (donde están las mesas de trabajo, las herramientas y las refacciones), y otros pueden funcionar ya sea como almacén o como centro de pintado y secado. La formalización de sus negocios siempre es un fenómeno en progreso. No todos tienen registros ante las diferentes autoridades económicas, hacendarias, de registro de nombre, otorgamiento de seguridad social a sus empleados. Salvo dos de los casos ya formalizados, la mayoría se encuentra en distintos niveles respecto de la formalización de sus actividades.

Podríamos decir que la cultura del trabajo del reparador, recuperando la noción de Reygadas (2012), está constituida por una individualidad que desarrolla los diversos proyectos de reparación/afinación/restauración a través de una combinación de saberes técnicos y artísticos aplicados a un caso concreto. En otras ocasiones, como las que este artículo reporta, se encabeza un trabajo colectivo con otros trabajadores (algunos de ellos parientes) que laboran bajo relaciones de subordinación y participan en diversas fases o partes del proyecto de servicios, bajo las directrices del técnico/artesano.

También utilizan las plataformas digitales para realizar una diversidad de actividades, entre ellas hacerse promoción, conseguir clientela, establecer los primeros contactos de la negociación sobre la reparación; comprar y vender acordeones y sus refacciones. La mayoría tiene como clientes a ciertos artistas famosos que les sirven de "ancla" o atractivo para la oferta de sus servicios ante quienes no los conocen.

\footnotetext{
${ }^{11}$ Agradezco esta importante información a Luisa Fernanda Patrón, del Grupo Tayer, quien ha seguido por décadas estos ciclos estacionales.
} 


\section{Saberes, ReGursos, Gonocimientos.}

LOS RECURSOS DEL ARTESANADO EN

UN CONTEXTO POSINDUSTRIAL Y POSMODERNO

Una vez que el instrumento llega al reparador con la necesidad específica o el problema descrito por el cliente, existe una distancia entre las necesidades para intervenir el instrumento y los conocimientos y recursos que posee el reparador. Entre ambos, el desafío técnico o estético puede generar una tensión de donde surgen nuevos conocimientos (nuevos sonidos o maneras de generarlos y nuevos conocimientos sobre materiales, piezas, mecanismos, estética del aparato), inclusive la certeza de aquello que no se es capaz de hacer. Presentamos una lista de conocimientos/saberes y recursos que suele usar el reparador de acordeones para hacer frente a los retos de su negocio.

\section{Conocimientos técnicos especificos}

Estos saberes se refieren a las cuatro áreas de intervención del acordeón descritas arriba, sobre las que haremos diversos apuntes. El conocimiento sobre los mecanismos centrales de generación de sonidos, es decir, entender la naturaleza específica del sonido en estos instrumentos, permite realizar las afinaciones o los cambios de tono. Debe estar complementado con el conocimiento de las escalas tonales, un oído educado y algún tipo de instrumento afinador mecánico, eléctrico o digital. Gracias a esto, el reparador puede saber cada una de las combinaciones de voces que dan por resultado el sonido "colombiano", "tejano" o "norteño" (escuchar audio 1). A este respecto, René Aguillón sostiene que no es necesario ser músico para desarrollar buen oído, pues aunque él y su hermano aprendieron de un músico (que fue su padre), todos los conocimientos que adquirieron fueron del lado de su padre como reparador; como en varios de los casos, no fue necesaria una formación musical integral para entender el funcionamiento del acordeón y lograr convertirse en reparadores. Aunque el principio es igual, estos saberes sobre los mecanismos de generación de sonidos se resuelven de modo distinto entre la diversidad de los acordeones diatónicos y cromáticos.

Los mecanismos periféricos de generación del sonido -los botones, brazos, válvulas y el fuelle- abren de manera importante el abanico de conocimientos necesarios sobre mecánica y ciencia de materiales, así como sus respectivos desgastes o degeneraciones. El reparador sabe entonces 
sobre distintas maderas, ceras, metales y sus aleaciones, telas y cintas, materiales de recubrimiento, soldaduras y remaches. Un caso ilustrativo es la cera que se aplica entre las voces. Según Daniel Martínez Valdés, existe una variedad de ceras que pueden utilizarse dependiendo del caso. Es importante, porque la mayoría de los reparadores usan cera de Campeche, pero no es funcional para la reparación. Es muy necesario utilizar un producto local que sirva para las condiciones climáticas de cada lugar. Dice que cuando llegan acordeones de Italia con cera de allá (que es la que utilizan por el clima templado), aquí ya no sirve, pues se deshace. En su taller emplea cera de abeja. Para los talleres hay dos tipos: cera de resina y cera de abeja. La cera de resina es conocida como cera de invierno, y la cera de abeja, como cera de calor. Y como en Nuevo León el clima según la estación es muy frío o muy caliente, lo que se necesita es una cera adecuada a la región. (Imagen 18)

Ambos conocimientos, sobre las voces y los mecanismos que las hacen sonar, exigen el manejo de ciertas herramientas. Las que se emplean en estos talleres son en su mayoría genéricas: desarmadores, cautín, lupas, diversidad de martillos, desarmadores, pinzas y punzones, además del afinador, principalmente digital, pero también analógico o manual. Pero también existen adaptaciones de herramientas e insumos para llevar a cabo su trabajo, que denotan ingenio y capacidad de improvisación, como en el caso de los generadores de aire o fuelles para hacer sonar las voces, que se construyen sobre diversos principios de funcionamiento (ver imágenes 18 y 10). Sobre la mesa de trabajo o por debajo de ella siempre se hallan estos fuelles que "resoplan las músicas". Soplarlas con la boca, además de cansado, impregna de bacterias los metales que terminarán siendo corroídos. Entonces, se ponen las voces sobre esa caja, se pisa el fuelle, se generará el sonido y el afinador marcará los tonos. Recuperando el concepto de "ontología del accidente", diremos que las diversas intervenciones del afinador-reparador-artesano pueden llegar a tener un carácter accidental 
que, a la vez, propicia la innovación, el desarrollo tecnológico y un mayor poder del técnico sobre la máquina.

Finalmente, los trabajos vinculados a la estética visual requieren extender los conocimientos a nácares plásticos, pinturas especializadas, técnicas de pintado y secado, dibujos y moldes. Enfocado en mejorar la imagen del acordeón a partir de diseños propios, Chuy Tamez es un caso de quien se especializa en conocimientos de materiales tanto para la restauración como para la estética. Fue necesario experimentar con diversos materiales y técnicas para lograr hacer los diseños que se imaginaba. Más allá de los conocimientos que tenía para hacer sus tareas, lo importante siempre ha sido la práctica, donde la mano de obra demuestra que es el factor determinante para que un trabajo quede bien hecho. Un ejemplo es el de la pintura, que exige cierto grado de especialización, conocimiento que comenzó a aprender pintando ataúdes y profundizó ahora con su taller. Curiosamente, Chuy ofrece el servicio de reparación y afinación de voces, pero no lo hace él sino que lo subcontrata con otro especialista.

En resumen, el conjunto de estos conocimientos permite identificar la calidad del instrumento por intervenir, así como la viabilidad y el posible costo de su intervención. La avalancha de productos chinos de los últimos años transformó el mercado, expandiéndolo por tipos de calidad/precio o "gamas" - como los llaman los reparadores, vendedores y ejecutantes-y diversificándolo en marcas y modelos, por lo que, para mantenerse en el mercado, el reparador también debe conocer esta diversidad.

\section{Conocimiento del mercado que atienden}

Este conocimiento abarca tanto las marcas y modelos y sus evoluciones a través del tiempo como los tipos y necesidades principales de sus clientes. Respecto de lo primero, Daniel Martínez ubica tres gamas relativas a la calidad y precio del acordeón: baja, media y alta. La gama baja está conformada por acordeones de menor calidad y precio, la mayoría de origen chino. Son producidos en serie y no hechos artesanalmente. Tienen unos tres años como promedio de vida y, antes de eso, requieren varias y costosas reparaciones, ya que sus materiales y piezas son de baja calidad. En el mercado que él conoce, los acordeones chinos son la mayoría, debido al bajo precio. Sus principales marcas son Yingjie, Melody, Farinelli, Rossetti y Solaris. Las reparaciones de éstos pueden ser más constantes, pero de menor costo. Rumbo a la gama media están Gabrielloni y el Parrot, tam- 
bién chinos. Habría una gama media constituida por los acordeones Hohner hechos en China, "pues la marca vendió su patente a un fabricante chino", explica el reparador. ${ }^{12}$ Dice que usan el Hohner Phanter chino (9 000 pesos) en una academia de acordeón en Monterrey. Identifica también acordeones italianos, chinos y alemanes, fabricados en Brasil, que circulan en el mercado regiomontano. La gama alta estaría constituida por los acordeones de dos marcas líderes en este tipo: Hohner y Gabanelli. De Hohner, estarían modelos como el Anacleto, Corona III o varios modelos de la marca Gabanelli. También hay otras marcas italianas (Brilingtton, Dino Baffetti). Su mercado es pequeño pues los precios oscilan entre los 30 mil y 120 mil pesos. Los consumidores de las gamas media y alta son personas que llevan ya varios años con el instrumento y buscan mejorar su ejecución, aumentar la calidad del sonido y empoderar su imagen, en una sinergia entre instrumento y ejecutante.

Otro conjunto de conocimientos se refiere al funcionamiento de las tecnologías de información y comunicación (TIC). Nos referimos a las distintas funciones del celular, aplicaciones para afinación, plataformas de redes sociales. Herbey López considera que las redes sociales son muy necesarias y las usa para promocionarse. Gracias a esto ya mucha gente le contacta incluso desde fuera del estado. Chuy confirma esta importancia y reconoce que representaron un punto clave para lograr el alcance que ahora tiene su negocio. Su caso podría tomarse como un verdadero fenómeno, pues tiene más seguidores que los demás reparadores, conseguidos en un tiempo récord, lo que le ha permitido expandir su negocio a escala regional. Esto nos lleva al tema de las redes y la circulación de los saberes.

${ }^{12}$ Libianel Marulanda (2020) reafirma de la siguiente manera el dicho de Martínez: "Igual que tantas fábricas y marcas reconocidas, la Hohner también consiguió capear la crisis de los años ochenta tras reducir los altos costos de su mano de obra, pagada en euros, recurriendo a China. El mercado poco a poco comienza a nutrirse de acordeones hechos en la patria de Mao y la indeseable sopa de murciélago. Por eso vemos hoy en los catálogos de ventas por internet los modelos clásicos como el Corona III, otros de menor costo y nuevo ropaje, como el Hohner Rey Vallenato, el Phanter que valen la mitad de los fabricados en Alemania. Incluso hay una línea no superior a las doscientas unidades, que le rinde tributo a la dinastía de los Zuleta" [famosos intérpretes y compositores de la Costa atlántica colombiana]. 
En su proceso de aprendizaje, Daniel Martínez comenzó a subir videos a YouTube de lo que hacía. Cuando menos esperó, recibió una notificación de España de alguien que buscaba aprender más del acordeón diatónico en México, por lo que pudieron tener intercambios de saberes sobre las culturas del acordeón en México y Europa. A su vez, esa relación le permitió conocer a una académica panameña, quien le ofreció especificaciones de la afinación del acordeón colombiano. Por su lado, Herbey López ha establecido conexiones en Colombia que le permiten importar piezas fabricadas en ese país, que son más baratas que las originales que se venden aquí y cuya venta deja muy poco margen de ganancia. Por otro lado, Martínez y los hermanos Aguillón reciben constantemente encargos desde Texas, mercado al que atendieron en su momento Santos Aguillón, el padre de éstos, y Rogelio Rodríguez, maestro de este último. Finalmente, en consonancia con lo que se dijo en el apartado anterior, los conocimientos que cuestan más trabajo a los reparadores, porque se tiene con ellos una especie de atracción-rechazo, son todos aquellos vinculados con las tareas de administración.

Como hemos visto hasta aquí, esta red entre reparadores para dar vida a instrumentos a través de su trabajo está condicionada, pero no determinada, por diferentes grados de poder y recursos, como la educación universitaria especializada, la pertenencia a dinastías musicales o la tradición familiar para la reparación.

\section{Conclusiones}

En términos de valor, el producto que puede ofrecer el reparador de acordeones se reflejaría, entre otras cosas, en el conocimiento sobre la estructura y el funcionamiento del acordeón; la diversidad y calidad de estos instrumentos y, por tanto, de los problemas comunes y cómo arreglarlos. Su saber incluye las distintas audiotopías que conviven en una megalópolis como Monterrey, es decir, aquellos sonidos vinculados a un sistema de significados que una comunidad revive en sus tradiciones, creencias y rituales. Su experiencia realizando estas labores le da prestigio por los trabajos hechos previamente. Posee y maneja herramientas especializadas que le permiten realizar esa tarea. Finalmente, no sólo tiene piezas o refacciones para sustituir las dañadas, conocimiento de dónde pueden ser conseguidas, sino capacidad para fabricarlas a partir de elementos varios. 
Con la evidencia presentada, Monterrey podría ser considerado como un centro regional o nacional de reparación.

El reparador es un técnico/artesano que realiza funciones sociales vitales alrededor del acordeón en la ciudad de Monterrey. Alargar la vida social del instrumento es quizá la principal. Cada vez que los reparadores aplican su conocimiento para volver a hacer funcionar la maquinaria, conseguir de nuevo el surgimiento del sonido o alterarlo deliberadamente a través de los servicios de una estética sonora, reviven un objeto que es expresión simbólica de una identidad sociorregional, que se actualiza a través del diálogo entre lo actual y lo pasado y fortalece la memoria cultural (Ragland, 2019). Simultáneamente, bajo la sensibilidad del capitalismo tardío, su trabajo puede orientarse a personalizar el acordeón a tal grado que podrá hablar por su dueño y ejecutante a través del arte de su acabado y apariencia, con lo cual deja de ser un instrumento hecho en serie, indiferente, indistinto, aunque nuevo.

La labor de los reparadores del acordeón pone al régimen de valor en una tensión constante, como ha sugerido Appadurai (1991). Por un lado, es un eslabón importante en la cadena global de las grandes empresas productoras. Reparar puede ser visto como resultado típico del consumo intensivo de las economías capitalistas. Pero, al mismo tiempo, como un acto de resistencia que impide ese mismo consumo intensivo. Los reparadores se caracterizan por el aprendizaje autodidacta y por la construcción de redes de saberes; buscan conocimientos incesantemente a través de la experimentación y práctica constante, así como a través del uso de portales, blogs y redes sociales. Lo anterior contrasta con la ausencia de escuelas especializadas en el acordeón, como la que existe en la ciudad de Querétaro para la construcción, reparación y restauración de instrumentos de cuerda frotada. ${ }^{13}$ La ausencia de producción nacional de este instrumento es seguramente una de las razones principales de la existencia de los reparadores. Como dice Victoria Novelo, parte de la explicación de la supervivencia de estos personajes "radica en la capacidad de flexibilidad y adaptación y en las estrategias que han debido desarrollar las unidades

\footnotetext{
${ }^{13}$ Se puede consultar la oferta académica de esta escuela en Escuela de Laudería en Querétaro, de Música en México: https://musicaenmexico.com.mx/escuela-de-lauderiaen-queretaro/, consultado el 30 de noviembre de 2020.
} 
domésticas que especializan a sus miembros en distintas tareas para allegarse ingresos" (Novelo, 2003: 14-15).

La amplia disponibilidad de acordeones, fenómeno que comenzó a ocurrir desde hace veinte años, cuando los instrumentos chinos empezaron a llegar al mercado regiomontano, es otro de los factores que han impulsado el aumento de los servicios de reparación. Varios de nuestros entrevistados han dicho que, si no fuera por la existencia de este tipo de acordeones, no hubieran tenido oportunidad de hacerse de uno sino hasta mucho tiempo después.

En este sentido, mientras algunos sueñan y trabajan para la fabricación de un acordeón mexicano, otros tratan de acoplarse a la realidad global trayendo acordeones chinos de cada vez mayor calidad, vendiendo una marca personalizada. Finalmente, viven en el juego de fuerzas económicas globales, donde las economías centrales están pagando el precio por producir barato en China, a riesgo de ir perdiendo el control de su tecnología. Hoy, los chinos no sólo han inunda23. La acordeonista Rocío Ruiz, y el grupo Las Neri, durante su durante su participación en el 5 Festival de acordeón Hohner

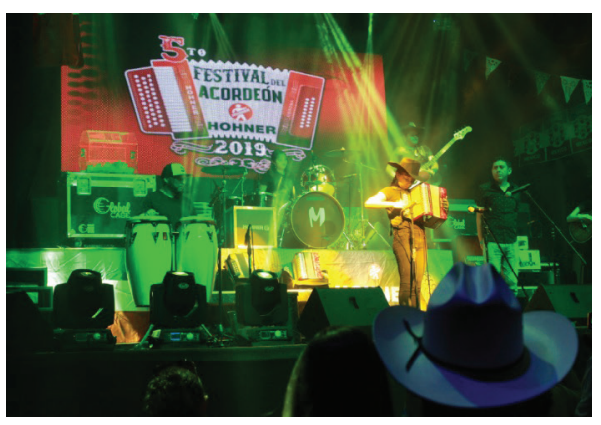
do el mercado de acordeones, sino que su disponibilidad de gamas media y media alta comienza a preocupar a las grandes compañías, quienes ahora están cada vez más presentes en los festivales de los que se habló al principio de este artículo (ver imagen 23). Uno de los reparadores comenta respecto de este fenómeno: "los chinos sólo están reclamando lo que fue su idea".

\section{BIBLIGORAFÍA}

Appadurai, Arjun (1991). La vida social de las cosas. Perspectiva cultural de las mercancias. Ciudad de México: Grijalbo.

Arzaluz, Socorro y Efrén Sandoval (2018). Cruces y retornos en la región del noreste mexicano en en el alba del siglo XXI. Tijuana: EL COLEF. 
Bates, Eliot (2012). "The Social Life of Musical Instruments". Ethnomusicology, vol. 56, núm. 3, pp. 363-395. https://doi.org/10.5406/ethnomusicology.56.3.0363

Becker, Howard S. (2008). Los mundos del arte. Sociología del trabajo artístico. Buenos Aires: Universidad Nacional de Quilmes.

Blanco, Darío (2018). La cumbia como matriz sonora de Latinoamérica. Identidad y cultura continental. Antioquia: Universidad de Antioquia.

Blanco, Darío (2013). Los colombias y la cumbia en Monterrey. Identidad, subalternidad y mundos de vida entre inmigrantes urbanos populares. San Nicolás de los Garza: UANL.

Cerutti, Mario y Tania Hernández (2001). "Frontera y desarrollo empresarial en el norte de México (1850-1910)", Frontera Norte, vol. 13, núm. especial 2, pp. 283-301.

Contreras, Camilo (coord.) (2010). Ecos y colores de la colonia Independencia. Monterrey: CONARTE.

Dawe, Kevin (2012). "The Cultural Study of Musical Instruments", en Martin Clayton, Trevoy Herbert y Richard Middleton (ed.), The Cultural Study of Music. Nueva York: Routledge, pp.195-205.

Díaz, Luis (2016). Historia de la música norteña mexicana. México: Plaza y Valdés.

Esquivel Hernández, Gerardo (2015). "Desigualdad extrema en México. Concentración del poder económico y político”. Ciudad de México: ОХFАM México. Recuperado de https://www.oxfammexico.org/sites/ default/files/desigualdadextrema_informe.pdf, consultado el 03 de noviembre de 2020.

Fuente, Daniel de la (2015, 3 de mayo). "El otro rey del acordeón". El Norte, p. 12

Garza, Luis Martín (2006). Raíces de la música regional de Nuevo León. Monterrey: CONARTE.

Godina, Ramiro (2016). "Bajo sextos en Monterrey”, en Luis O. Montoya y Gabriel Medrano (coord.), Historia social de las músicas populares latinoamericanas. Una visión desde México. Guanajuato: Universidad de Guanajuato, pp. 109-136.

Hernández-León, Rubén (2008). Metropolitan Migrants. The Migration of Urban Mexicans to the United States. Los Angeles: University of California Press. https://doi.org/10.1525/9780520942462 
Hernández Vaca, Víctor (2008). ¡Que suenen pero que duren! Historia de la laudería en la cuenca del Tepalcatepec. Zamora: El Colegio de Michoacán.

Kopytoff, Igor (1991). "La biografía cultural de las cosas: la mercantilización como proceso", en Arjun Appadurai (ed.). La vida social de las cosas. Perspectiva cultural de las mercancías. México: Grijalbo y conaculTA, pp. 89-122.

Kies, Thomas (2013). "Artisans of Sound: Persisting Competitiveness of the Handcrafting Luthiers of Central Mexico". Ethnomusicology Forum, vol. 22, núm. 1, pp. 71-88. http://dx.doi.org/10.1080/1741 1912.2013.775716

Latham, Alisson (2008). Diccionario Enciclopédico de la Música, México: FCE.

Lee, Deborah (2020). "Hornbostel-Sachs Classification of Musical Instruments", en Knowledge Organization, vol. 47, núm. 1, pp. 72-91. https://doi.org/10.5771/0943-7444-2020-1-72.

Libin, Laurence (2009). "Musical Instruments in Cultural Context", en Lucero Enríquez (coord.), Harmonia Mundi: los instrumentos sonoros en Iberoamérica, siglos XVI al XIX. México: UNAM, pp. 17-33.

Marulanda, Libianel (2020, 11 de mayo). "Oda al acordeón en tiempos de la peste". El Quindiano. Recuperado de https://www.elquindiano. com/noticia/18759/oda-al-acordeon-en-tiempos-de-la-peste, consultado el 03 de noviembre de 2020.

Montoya, Luis y Gabriel Medrano de Luna (2018). "El acordeón norteño mexicano y el transnacionalismo musical cosmopolita en las periferias". Acta Universitaria, vol. 28, núm. 2, pp. 83-100. https://doi. org/10.15174/au.2018.1319

Montoya, Luis (2013). jArriba el Norte! Música de acordeón y bajo sexto. México: INAH-CONACULTA.

Nettl, Bruno (2015). The Study of Ethnomusicology. Chicago: University of Illinois Press.

Novelo, Victoria (2006). La capacitación de los artesanos en México. Una revisión. México: Plaza y Valdés.

Olvera, José Juan (2005). Colombianos de Monterrey. Origen de un gusto musicaly su papel en la construcción de una identidad. Monterrey: CONARTE.

Ortega y Gasset, José (2000). Meditaciones de la técnica y otros ensayos sobre ciencia y filosofia. Madrid: Alianza.

Pareyón, Gabriel (2006). Diccionario Enciclopédico de Música en México. México: Universidad Panamericana. https://doi.org/10.31885/2018.00004 
Peña, Manuel (1996). The Texas-Mexican Conjunto. Austin: University of Texas Press

Polanyi, Karl (1976). "El sistema económico como proceso institucionalizado". Maurice Godelier (ed.), Antropología y economía. México: FCE, pp. 155-178.

Ragland, Cathy (2009). Música norteña: Mexican Migrants Creating a Nation Between Nations. Filadelfia: Temple University Press. https://doi.org/10.2307/j.ctt14btdjr

Ragland, Cathy (2019). Sounding the Past while Listening to the Present: Accordion Tuners as Auditory Culture Mediators in Tejano Conjunto Music. Manuscrito no publicado.

Ramos, Francisco (2016). "El acordeón en San Antonio, Texas (18551910)", en Luis O. Montoya y Gabriel Medrano (coords.), Historia social de las músicas populares latinoamericanas. Una visión desde México. Guanajuato: Universidad de Guanajuato, pp. 137-158,

Reygadas, José Luis (2012). Economías alternativas. Utopías, desencantos y procesos emergentes. México: Juan Pablos/UAM.

Reygadas, José Luis (2002). "Producción simbólica y producción material: metáforas y conceptos en torno a la cultura del trabajo". Nueva Antropología, vol. XVIII, núm. 60, febrero, 2002, pp. 101-119.

Riis, Morten (2013). "The Media Archaeological Repairman". Organised Sound, vol. 18, núm. especial 3, pp. 255-265. https://doi. org/10.1017/S1355771813000228

Rodríguez, Pablo (2001, 21 de Septiembre). Los microemprendimientos de la Economía Social en la Encuesta Permanente de Hogares [ponencia en congreso]. VIII Congreso Argentino de Antropología Social. Salta, Argentina. Recuperado de http://sedici.unlp.edu.ar/bitstream/handle/10915/5343/Documento_completo.pdf?sequence=1\&isAllowed=y, consultado el 3 de noviembre de 2020.

Sandoval, Efrén (2012). Infraestructuras transfronterizas: etnografia de itinerarios en el espacio social Monterrey - San Antonio. México: CIESAS.

Simonett, Helena (2012a). "Introduction", en Helena Simonett (ed.), The Accordion in the Americas. Klezmer, Polka, Tango, Zydeco, and More! Chicago: University of Illinois, pp. 1-18. https://doi.org/10.5406/illinois/9780252037207.001.0001 
Simonett, Helena (2012b). "From Old World to New Shores", en Helena Simonett (ed.), The Accordion in the Americas. Klezmer, Polka, Tango, Zydeco, and More! Chicago: University of Illinois, pp. 19-38. https://doi. org/10.5406/illinois/9780252037207.001.0001

\section{ENTREVISTAS}

Daniel Martínez, reparador y afinador de acordeones. Entrevistado por José Juan Olvera (trabajo de campo), Monterrey, Nuevo León, 27 de enero del 2016.

Feliciano Rodríguez Montes (Chanito Rodríguez), reparador de acordeones. Entrevistado por Alfonso Ayala Duarte (trabajo de campo), Reynosa, Tamaulipas, 12 de agosto del 2016.

Héctor Castillo, vendedor de acordeones. Entrevistado por José Juan Olvera (trabajo de campo), Monterrey, Nuevo León, 27 de enero del 2014.

Herbey López, reparador y afinador de acordeones. Entrevistado por José Juan Olvera (trabajo de campo), Monterrey, Nuevo León, 5 de mayo del 2016.

Jesús Tamez (Chuy Tamez Accordions), reparador/restaurador de acordeones. Entrevistado por Jacqueline Peña Benítez (trabajo de campo), Villa de Santiago, Nuevo León, 2 de diciembre del 2019.

Jhoniván Sáenz, músico, maestro y reparador de acordeones. Entrevistado por Jacqueline Peña Benítez y José Juan Olvera (trabajo de campo), Monterrey, Nuevo León, 4 de febrero del 2019 y 14 de abril de 2020

Ricardo y René Aguillón (hijos del reparador Santos Aguillón, reparadores de acordeones. Entrevistados por José Juan Olvera (trabajo de campo), Monterrey, Nuevo León, 5 de diciembre del 2019. 
Fosé Juan Olvera Gudiño es profesor-investigador del CIESAS-Noreste. Sociólogo, maestro en Comunicación, doctorado en Humanidades con especialidad en Comunicación y Estudios Culturales por el Tecnológico de Monterrey. Miembro del Sistema Nacional de Investigadores, nivel 1. Ha dirigido el proyecto: "Procesos regionales de construcción de la cultura en el noreste de México y sur de Texas: los casos del hip hop y la música norteña”, financiado por el CONACYT. Sus publicaciones recientes: 2018. Economías del rap en el noreste de México. Emprendimientos y resistencias alrededor de la música popular. México, Casa Chata, y coordinó el libro colectivo Economías de la música norteña. México, Casa Chata, actualmente en prensa.

Jacqueline Peña Benitez es investigadora asociada al CIESAS en la modalidad de becaria de capacitación en técnicas y metodologías de la investigación. Forma parte del proyecto de investigación Muerte y resurrección en la Frontera. Procesos de construcción de la cultura en el noreste de México y Texas, que financió el CONAcYT. Es egresada de la carrera de Sociología de la Universidad Autónoma de Nuevo León. 
Vol. 4, núm. 8, septiembre 2021-febrero 2022

https://encartes.mx

ISSN: 2594-2999

\section{TEMÁTICAS}

MÚSICA POPULAR, GLOBALIZAGIÓN Y EGONOMÍA.

INTRODUGGIÓN

José Juan Olvera Gudiño

Shinji Hirai

COMPOSIGIÓN DE NARGOCORRIDOS

EN TIEMPO REAL: GONSTRUGGIÓN SOGIOMUSIGAL

DEL 17 DE OGTUBRE EL GULIACANAZO

César Jesús Burgos Dávila

Julián Alveiro Almonacid Buitrago

PAISAJES SONOROS DE LA MIGRAGIÓN.

MÚSICA, EMOGIONES Y GONSUMO EN LOS

GIRGUITOS MIGRATORIOS TEXAS-NORESTE DE MÉXICO

Shinji Hirai

Raquel Ramos Rangel

GONSTRUGGIÓN DEL AMOR ROMÁNTICO, IDEALES DE PAREJA Y RELAGIONES DE GÉNERO

DESDE LA LÍRIGA DE LA MÚSIGA NORTEÑA Y LA

BANDA SINALOENSE

Mariángel Estefanía Urrecha Arce

Ana Isabel Sánchez Osuna

César Jesús Burgos Dávila

LAS GONQUISTAS DEL ACORDEÓN:

DEL VIEJO MUNDO A NUEVOS HORIZONTES

Helena Simonett

LAS VIDAS DEL ACORDEÓN.

REPARADORES Y VIDA SOGIAL DE UN

INSTRUMENTO MUSICAL EN MONTERREY

José Juan Olvera Gudiño

Jacqueline Peña Benítez

GONSTRUGGIÓN DE BAJO SEXTOS EN TRES GIUDADES

DE GOAHUILA, MÉXICO. TRADIGIÓN E INNOVAGIÓN EN LA

IMAGEN VISUAL DEL INSTRUMENTO

Ramiro Godina Valerio 


\section{REALIIDADES SOGIOGULTURALES}

"SUS MIRADAS EN NUESTRA MEMORIA".

EL GRAFFITI COMO ESTRATEGIA DISCURSIVA FRENTE A LAS

DESAPARIGIONES FORZADAS EN LA ZONA DE GÓRDOBA-ORIZABA

Celia del Palacio

David Humberto Torres García

MARÍA ARCELIA DÍAZ (1896-1939): FEMINISTA,

TRABAJADORA TEXTIL, LÍDER SINDIGAL Y PIONERA DE

POLÍTICAS SOGIALES Y LABORALES EN ZAPOPAN

María Teresa Fernández Aceves

REVUELTOS, GRIJOS Y PUCHUNCOS: RAGIALIZAGIÓN, IDENTIDAD Y MESTIZAJE EN UN PUEBLO DE LA

COSTA GHICA DE GUERRERO

Giovanny Castillo Figueroa

\section{ENCARTES MULTIMEDIA}

"ALTARES TACHEROS": MINIETNOGRAFÍAS AZAROSAS

DE LA VIDA (RELIGIOSA) COTIDIANA

Alejandro Frigerio

IMÁGENES DE LA GONQUISTA EN TLAGOAGHISTLAHUAGA, GUERRERO: UNA DE TANTAS HISTORIAS...

Carlo Bonfiglioli

\section{ENTREVISTAS}

ENTRE REGIONES: CONVERSAGIÓN GON

PEDRO TOMÉ Y ANDRÉS FÁBREGAS

Entrevista realizada por Rafael Omar Mojica González

\section{DISGREPANCIAS}

LA PANDEMIA. AÑo 2

EXPERIENGIAS DIFERENGIADAS, DILEMAS GOMPARTIDOS Y REFLEXIONES MÚLTIPLES DESDE LA ANTROPOLOGÍA MÉDICA EN TORNO A LA GOVID 19

Rosa María Osorio, Sahra Gibbon y Mark Nichter

Moderadoras: Paola $\mathrm{M}^{\mathrm{a}}$ Sesia, Lina Rosa Berrio Palomo 


\section{RESEÑAS GRÍTICAS}

OKTUBRE, EL MONTAJE DE UNA ÉPOGA O

"EL ROGK COMO TODO LLANTO"

María Mónica Sosa Vásquez

DIÁLOGOS TRASATLÁNTICOS: LAS RUTAS DEL GREER. GIRGULAGIÓN, RELOGALIZAGIÓN Y REINTERPRETAGIÓN DE LA TRADICIÓN ORISHA

Gabriela Castillo Terán

PROTESTANTISMOS INTERAMERICANOS

Ezer Roboam May May 
Ángela Renée de la Torre Castellanos

Directora de Encartes

Arthur Temporal Ventura

Editor

Verónica Segovia González

Diseño y formación

Cecilia Palomar Verea

María Palomar Verea

Corrección

Saúl Justino Prieto Mendoza

Difusión

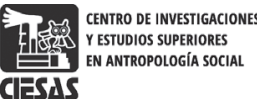

CFSAS
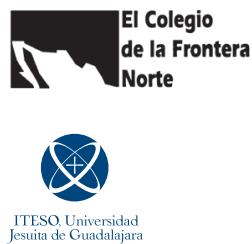

Equipo de coordinación editorial

Renée de la Torre Castellanos Directora de Encartes - Rodrigo de la Mora Pérez Arce iteso - Arcelia Paz ciesas-Occidente - Santiago Bastos Amigo ciesas-Occidente Manuela Camus Bergareche Universidad de Guadalajara - Olivia Teresa Ruiz Marrujo El cOLEF - Christian Omar Grimaldo Rodríguez ITESO

\section{Comité editorial}

Carlos Macías Richard Director general de ciesas - Alberto Hernández Hernández Presidente de El cOLEF David González Hernández Director del Departamento de Estudios Socioculturales del ITESO - Julia Esther Preciado Zamora ciesas-Occidente - María Guadalupe Alicia Escamilla Hurtado Subdirección de difusión y publicaciones de CIESAS - Érika Moreno Páez, Coordinadora del departamento de publicaciones de El cOLEF Manuel Verduzco Espinoza Director de la Oficina de Publicaciones del ITEso - José Manuel Valenzuela Arce El COLEF • Luz María Mohar Betancourt ciesas-Ciudad de México • Ricardo Pérez Monfort Ciesas-Ciudad de México - Sévérine Durin Popy Ciesas-Noreste - Carlos Yuri Flores Arenales Universidad Autónoma del Estado de Morelos $•$ Sarah Corona Berkin Decs/Universidad de Guadalajara $•$ Norma Iglesias Prieto San Diego State University - Camilo Contreras Delgado El COLEF • Alejandra Navarro Smith ITESO

Cuerpo académico asesor

Alejandro Frigerio

Universidad Católica

Argentina-Buenos Aires

Alejandro Grimson

Usam-Buenos Aires

Alexandrine Boudreault-Fournier

University of Victoria-Victoria

Carlo A. Cubero

Tallinn University-Tallin

Carlo Fausto

UFRJ-Rio de Janeiro

Carmen Guarini

UBA-Buenos Aires

Caroline Perré

Centro de Estudios Mexicanos y

Centroamericanos-Ciudad de

México

Clarice Ehlers Peixoto

UERJ-Rio de Janeiro
Claudio Lomnitz

Columbia-Nueva York

Cornelia Eckert

UFRGS-Porto Alegre

Cristina Puga

unAM-Ciudad de México

Elisenda Ardèvol

Universidad Abierta de

Cataluña-Barcelona

Gastón Carreño

Universidad de

Chile-Santiago

Gisela Canepá

Pontificia Universidad

Católica del Perú- Lima

Hugo José Suárez

unam-Ciudad de México

Jesús Martín Barbero ${ }^{\dagger}$

Universidad Javeriana-Bogotá

\section{Julia Tuñón}

INAH-Ciudad de México

María de Lourdes Beldi

de Alcantara

UsP-Sao Paulo

Mary Louise Pratt

NYU-Nueva York

Pablo Federico Semán

CONICET/UnSAM-Buenos Aires

Renato Rosaldo

NYU-Nueva York

Rose Satiko Gitirana Hikji

usp-Sao Paulo

Rossana Reguillo Cruz

ITESO-Guadalajara

Sarah Pink

RMTT-Melbourne

Encartes, año 4, núm 8, septiembre 2021-febrero 2022, es una revista académica digital de acceso libre y publicación semestral editada por el Centro de Investigaciones y Estudios Superiores en Antropología Social, calle Juárez, núm. 87, Col. Tlalpan, C. P. 14000, México, D. F., Apdo. Postal 22-048, Tel. 548735 70, Fax 565555 76, encartesantropologicos@ciesas.edu.mx. El Colegio de la Frontera Norte Norte, A. G., Carretera Escénica Tijuana-Ensenada km 18.5, San Antonio del Mar, núm. 22560, Tïjuana, Baja California, México, Tel. +52 (664) 631 6344, e Instituto Tecnológico y de Estudios Superiores de Occidente, A. C., Periférico Sur Manuel Gómez Morin, núm. 8585, Tlaquepaque, Jalisco, Tel. (33) 3669 3434. Directora de la revista: Ángela Renée de la Torre Castellanos. Alojada en la dirección electrónica https://encartes.mx. ISSN: 2594-2999. Las opiniones expresadas por los autores no necesariamente reflejan la postura de la revista. Se autoriza la reproducción parcial de los materiales publicados siempre y cuando se haga con fines estrictamente no comerciales y se cite la fuente. Salvo excepciones explicitadas, todo el contenido de la publicación está bajo una Licencia Creative Commons Atribución-NoComercial 4.0 Internacional. 